\title{
The testosterone-dependent and independent transcriptional networks in the hypothalamus of Gpr54 and Kiss1 knockout male mice are not fully equivalent
}

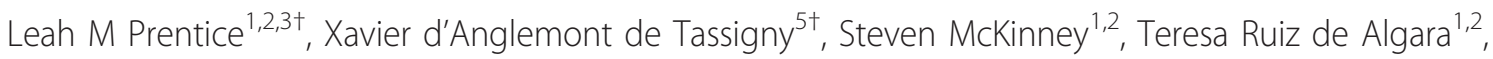
Damian Yap ${ }^{1,2}$, Gulisa Turashvili, ${ }^{1,2}$, Steven Poon ${ }^{1,2}$, Margaret Sutcliffe ${ }^{1,2}$, Pat Allard ${ }^{1,2}$, Angela Burleigh ${ }^{1,2}$, John Fee Fen $^{1,2}$ , David G Huntsman ${ }^{2,3,4}$, William H Colledge 5 $^{*}$ and Samuel AJ Aparicio ${ }^{1,2^{*}}$

\begin{abstract}
Background: Humans and mice with loss of function mutations in GPR54 (KISS1R) or kisspeptin do not progress through puberty, caused by a failure to release $\mathrm{GnRH}$. The transcriptional networks regulated by these proteins in the hypothalamus have yet to be explored by genome-wide methods.

Results: We show here, using 1 million exon mouse arrays (Exon 1.0 Affymetrix) and quantitative polymerase chain reaction (QPCR) validation to analyse microdissected hypothalamic tissue from Gpr54 and Kiss1 knockout mice, the extent of transcriptional regulation in the hypothalamus. The sensitivity to detect important transcript differences in microdissected RNA was confirmed by the observation of counter-regulation of Kiss1 expression in Gpr54 knockouts and confirmed by immunohistochemistry (IHC). Since Gpr54 and Kiss 1 knockout animals are effectively pre-pubertal with low testosterone (T) levels, we also determined which of the validated transcripts were T-responsive and which varied according to genotype alone. We observed four types of transcriptional regulation (i) genotype only dependent regulation, (ii) T only dependent regulation, (iii) genotype and T-dependent regulation with interaction between these variables, (iv) genotype and T-dependent regulation with no interaction between these variables. The results implicate for the first time several transcription factors (e.g. Npas4, Esr2), proteases (KIk1b22), and the orphan 10-transmembrane transporter TMEM144 in the biology of GPR54/kisspeptin function in the hypothalamus. We show for the neuronal activity regulated transcription factor NPAS4, that distinct protein over-expression is seen in the hypothalamus and hippocampus in Gpr54 knockout mice. This links for the first time the hypothalamicgonadal axis with this important regulator of inhibitory synapse formation. Similarly we confirm TMEM144 upregulation in the hypothalamus by RNA in situ hybridization and western blot.
\end{abstract}

Conclusions: Taken together, global transcriptional profiling shows that loss of GPR54 and kisspeptin are not fully equivalent in the mouse hypothalamus.

\footnotetext{
*Correspondence: whc23@cam.ac.uk; saparicio@bccrc.ca

+ Contributed equally

${ }^{1}$ Molecular Oncology and Breast Cancer Program, British Columbia Cancer Research Centre, 675 West 10th Avenue, Vancouver, BC, V5Z 1L3, Canada

${ }^{5}$ Reproductive Physiology Group, Department of Physiology, Development, and Neuroscience, University of Cambridge, Downing Street, Cambridge,CB2

3EG, UK

Full list of author information is available at the end of the article
} 


\section{Background}

In 2003 it was discovered that the kisspeptin activated GPR54 receptor is required for maturation and activity of the hypothalamic-pituitary-gonadal axis $[1,2]$. It has been established subsequently that kisspeptin (Kp) binding to GPR54 releases gonadotropin releasing hormone (GnRH) from the hypothalamus to stimulate the pituitary-gonadal axis in a multitude of species including humans [3-15]. In mice, GnRH neurons express Gpr54 from birth and more GnRH neurons acquire expression during pubertal development [16]. In rodents, Kp is expressed by neurons in the arcuate nucleus (ARC) of the hypothalamus and also in the rostral periventricular area of the 3rd ventricle (RP3V) which includes the anteroventral periventricular nucleus (AVPV). Rising estrogen levels have a positive feedback effect on Kp expression in the AVPV $[17,18]$ to initiate the LH surge required for ovulation in females [19-21]. Conversely, estrogen and testosterone have a negative feedback effect on Kp expression in the ARC that is regulated through the estrogen receptor alpha $(E R \alpha)$ or through the androgen receptor (AR) respectively [17-19,21,22].

Despite the critical importance of GPR54/kisspeptin in mammalian fertility, little is known of the upstream and downstream gene regulatory networks for kisspeptin signaling in the hypothalamus. The feedback relationships between GPR54 and kisspeptin are incompletely understood. To address the question of which genes are codependent on GPR54 and kisspeptin and whether the transcriptional networks of GPR54 deficient mice and kisspeptin deficient mice are equivalent, we have taken advantage of the knockout mice we generated during the initial discovery of the GPR54-kisspeptin axis. Gpr54 and Kiss 1 knockout mice model the hypogonadotropic hypogonadism $(\mathrm{HH})$ found in humans with GPR54 mutations $[2,10,23]$. Although the neuronal inputs and projections of GPR54 and kisspeptin are barely described, the hypothalamus is clearly a key site of interest, since the action of kisspeptin on neurons co-expressing GPR54 and GnRH are key to the function of the axis. We therefore chose to focus on determining the hypothalamic transcription network, initially scanning the transcriptome with Affymetrix Exon 1.0 arrays. These exon arrays contain probes for all of the known and predicted gene exon sequences in the mouse genome, thus representing a near complete, transcriptome profiling method.

Using micro-dissected hypothalamic tissues to isolate RNA from our mutant mice, we first set out to define the transcriptional differences between the knockout mice. Since the GPR54-kisspeptin axis is subject to hormonal feedback and the knockout mice are pre-pubertal, we also tested the hormonal dependence/independence of each differentially expressed transcript. To avoid variation in gene expression due to fluctuations in the levels of circulating hormones during the female estrous cycle, only male mice and testosterone $(\mathrm{T})$ exposure were used in this study. We utilized a study designed to define purely $\mathrm{T}$-regulated transcription, purely genotype-dependent transcription and transcription dependent on both $\mathrm{T}$ and genotype, with interaction or no interaction between these variables.

\section{Results \\ Microarray identification of deregulated transcripts from Gpr54 and Kiss1 knockout mice hypothalami}

We first isolated RNA from micro-dissected hypothalamic tissue of knockout and wild-type mice and hybridized this to Exon 1.0 arrays (methods). We compared quantile normalized probe intensity values from Affymetrix whole mouse exon array chips where hybridization was performed with wild-type (WT), Gpr54 knockout (GKO) or Kiss1 knockout (KKO) hypothalamic RNA. Affymetrix results were compared between genotypes, specifically gene expression of all wild-type mice were grouped together and compared with all knockout mice grouped together (WT vs KO) or with Kiss1 knockout mice alone (WT vs KKO) or Gpr54 knockout mice alone (WT vs GKO). Additionally, Gpr54 knockout mice were compared with Kiss1 knockout mice (GKO vs KKO) to give a total of four groups (Figure 1). Gene level and exon level summarization was used in the comparisons and from each of these we selected genes showing a $p$-value $<0.05$ and an expression fold difference of 1.5 or greater, as candidates for further analysis (yellow highlighted regions in the volcano plots shown in Additional file 1).

This analysis yielded 198 unique genes, putatively exhibiting differential transcription between wild-type mice and/or either knockout (Figure 1). Several global features of the transcription network were apparent in these data. First, we analyzed the functional groupings of genes and noted that signaling molecules and enzymes were the two largest biochemical classes (Figure 1). Next, we examined possible network overlaps by analyzing separately for the GKO and KKO differential gene lists, the possible network connectivity using a curated database of functional interactions, as previously described (Ingenuity pathways, http://www.ingenuity. com, methods). Interestingly both the GKO (Additional files 2 and 3) and KKO (Additional files 3 and 4) networks show apparently common nodes of signaling via HNF4a and growth factor signaling pathways, however many differences are also seen in the putative networks, suggesting that the effects of Kiss1 knockout may not be fully equivalent to Gpr54 knockout. Consistent with this notion, we noticed fewer statistically significant gene level ( 2 vs 29, Additional file 5: Table S1) and exon level 


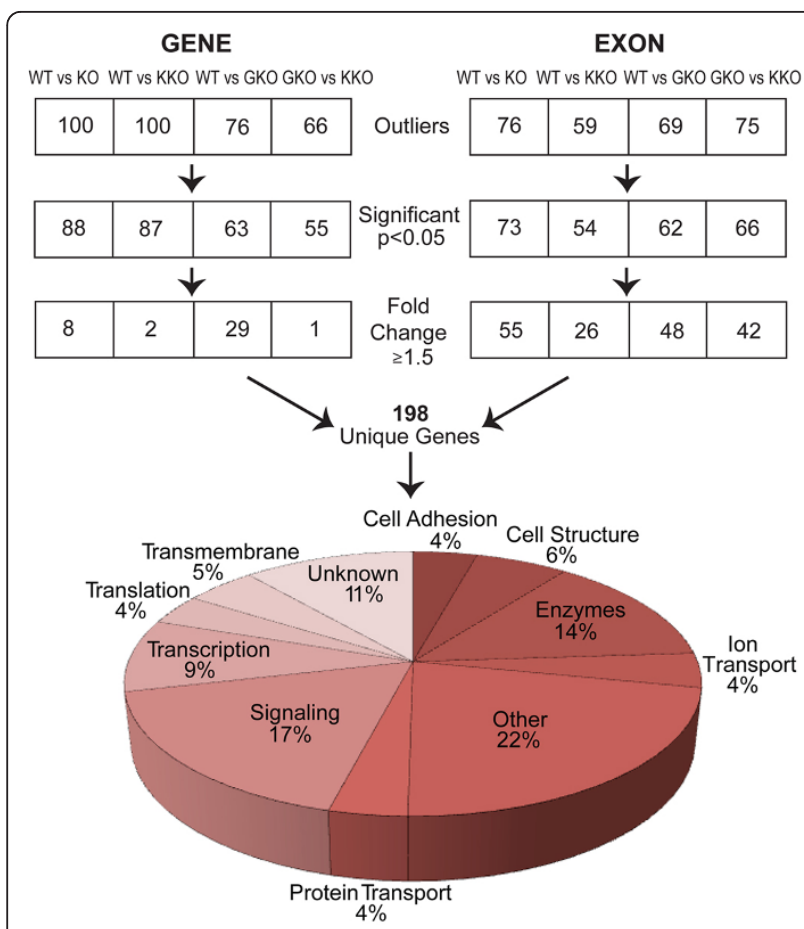

Figure 1 Classification of 198 differentially expressed genes in the discovery set. The figure shows the number of significant genes identified at each step of the microarray analysis procedure with subsequent filtering steps for statistical significance and fold change expression differences. WT vs KO represents a joint comparison of all data, whereas WT vs GKO and KKO represent separated analyses. The numbers of genes falling through the analysis are shown separately for gene level and exon level summarization. The pie chart shows the grouping of molecular functions for the 198 gene set.

(26 vs 49) transcription differences for KKO mice compared with GKO. To explore this possibility further we decided to validate a subset of the most pronounced array expression differences by QPCR. Genes showing transcription differences were prioritized in the following order: strength of expression, consistency of differences between knockouts, known or suspected roles in hormonal regulation, and finally the availability of quenching QPCR probes for low density 384 well QPCR plate analysis. Within these criteria, all transcription factors, transmembrane receptors, and signaling molecules that were available were included, resulting in a total of 72 genes (Additional file 6: Table S2, non-bolded genes). QPCR control probe sets for $18 \mathrm{~S}$ rRNA and Gapdh were included in each array as loading controls and we also selected a number of genes of interest (Additional file 6: Table S2, bold genes) based on their known role in gonadotropic signaling, that were not differentially expressed by microarray analysis. Thus a total of 95 genes were re-validated by microplate QPCR analysis (Additional file 6: Table S2).
Table 1 Discovery set genes showing QPCR validated transcriptional differences between WT and KO (Gpr54 or Kiss 1)

\begin{tabular}{ccccc}
\hline & \multicolumn{2}{c}{ GKO vs WT } & \multicolumn{2}{c}{ KKO vs WT } \\
\hline $\begin{array}{c}\text { Gene } \\
\text { Target }\end{array}$ & FC (95\%Cl) & Direction & FC (95\%Cl) & Direction \\
\hline Abca8a & $1.85(1.33-2.59)$ & Up & $1.97(1.33-2.90)$ & Up \\
Esr1 & $1.62(1.37-1.92)$ & Up & $1.54(1.32-1.78)$ & Up \\
Kiss1 & $14.03(10.86-18.11)$ & Up & N.A. & N.A. \\
Mmp2 & $1.51(1.18-1.94)$ & Up & n.S. & n.S. \\
Npas4 & $2.60(2.09-3.25)$ & Up & n.S. & n.s. \\
Lrdd & n.s. & n.s. & $1.80(1.29-2.51)$ & Up \\
Tmem144 & n.s. & n.s. & $2.61(2.21-3.08)$ & Up \\
\hline
\end{tabular}

$\mathrm{FC}=$ fold change, $\mathrm{Cl}=$ confidence interval, n.s. = not significant, N.A. = not applicable. GKO = GPR54 knockout, KKO = Kisspeptin knockout.

We used a 384 well plate QPCR array to assay each gene at least 3 times per sample (technical replicates) and 3 biological replicates of RNA prepared from micro-dissected hypothalamic tissue from wild-type, GKO and KKO mice. After analysis of the count $(\mathrm{Ct})$ values by a linear mixed effects model, genes showed statistically significant differential expression in one of the groups, 7 of which had a fold change $\geq 1.5$; two of these were genes of interest (Esr1, Mmp2) and one was a control (Kiss1; Table 1). All genes with a statistically significant fold change were carried forward for further analysis.

\section{Analysis of hormone-dependent and independent hypothalamic gene transcription in Gpr54 and Kiss 1 knockout mice}

Array expression analysis of micro-dissected hypothalamic samples revealed significant differential transcription between genotypes. However, since GKO and KKO mice fail to undergo puberty an unknown number of these transcriptional differences could be explained by the hormonal milieu. To address this, we tested which of these genes exhibited hormonally responsive transcription, by measuring transcriptional differences in the presence or absence of testosterone (T). WT, GKO and KKO male mice were castrated and implanted with either a sham silastic capsule, or a $\mathrm{T}$ containing capsule (characteristics of the mice used in Additional file 7: Table S4). After 4 weeks exposure, the mice were killed, the hypothalamus micro-dissected, and the RNA extracted. To confirm exposure to $\mathrm{T}$, we measured plasma free testosterone; KKO mean free testosterone $4.0 \mathrm{pg} / \mathrm{ml}(\mathrm{SD} \pm 1.5)$, GKO mean free testosterone 5.8 $\mathrm{pg} / \mathrm{ml}(\mathrm{SD} \pm 2.7)$, and WT mean testosterone $5.3 \mathrm{pg} / \mathrm{ml}$ ( $\mathrm{SD} \pm 1.5$ ) with zero free testosterone in the castrate/ empty silastic implant group. Each gene was assayed with at least 4 technical replicates and 3 biological replicates. To reduce the risk of loss of data due to genotype 
Table 2 Pure hormonal $(\mathrm{T})$ responsive genes

\begin{tabular}{ccccc}
\hline \multicolumn{5}{c}{ Hormonal Effect } \\
\hline Genotype & Gene Target & FC (95\%Cl) & Direction & $\boldsymbol{p}$-value \\
\hline GKO & Abca8a & $1.57(1.33-1.87)$ & Down & $2.83 \mathrm{E}-05$ \\
GKO & Klk1b22 & $2.16(1.43-3.25)$ & Down & 0.0042 \\
KKO & Gnrhr & $2.33(1.63-3.33)$ & Down & 0.0009 \\
\hline
\end{tabular}

$\mathrm{FC}=$ fold change, $\mathrm{Cl}=$ confidence interval, $\mathrm{Dir}=$ direction of change, relative to $\mathrm{T}$. GKO = GPR54 knockout, $\mathrm{KKO}=$ Kisspeptin knockout.

or hormonal effect on loading controls, we used two independent loading controls, $18 \mathrm{~S}$ rRNA and Gapdh. The data were analyzed separately using a linear mixed effects model (methods). We analyzed GKO and KKO mice separately in a $2 \times 2 \times 2$ design, considering gene (test, loading control), treatment $(\mathrm{T}+\mathrm{T}-\mathrm{T})$ and genotype (WT, GKO or KKO) as categorical variables. Tables 2 , 3,4 , and 5 summarize the statistically significant $(\mathrm{p}<$ 0.05 ), greater than 1.5 fold expression difference, model results for four classes of variation: (i) purely hormonedependent transcription (ii) purely genotype-dependent transcription (iii) hormone and genotype-dependent transcription but with no interaction between these variables and (iv) hormone and genotype-dependent transcription, with co-dependence (interaction) between these variables. Since two loading controls were used, these are also reported separately as they were treated independently in the analysis. Small differences with loading controls were noted, resulting in differences of interaction between genotype and hormone responsiveness for a few transcripts at statistical boundaries of significance. Nevertheless, the direction and magnitude of effects were consistent for all genes, with both control probes. We noted fewer statistically significant transcript regulation effects in the KKO mice, mirroring the initial observations from microarrays. Nevertheless, several genes (eg Klk1b22, Gnrhr, Tmem144) were regulated in common with GKO mice, albeit with effects of different magnitude. Several of the statistically significant QPCR results are of small absolute magnitude and considering the variances of the loading controls between genotypes and treatments, we suggest that interpretation of differences of less than 1.5 fold may not be meaningful (full

Table 3 Pure genotype effect genes

\begin{tabular}{ccccc}
\hline \multicolumn{5}{c}{ Genotype Effect } \\
\hline Genotype & Gene Target & FC (95\%Cl) & Direction & $p$-value \\
\hline GKO & Esr2 & $1.63(1.46-1.82)$ & Down & $4.10 \mathrm{E}-10$ \\
GKO & Hhip & $1.63(1.46-1.82)$ & Down & $4.68 \mathrm{E}-10$ \\
GKO & Lhcgr & $1.61(1.30-1.99)$ & Down & 0.0042 \\
GKO & Npas4 & $1.65(1.45-1.87)$ & Down & $2.06 \mathrm{E}-08$ \\
KKO & Tmem144 & $1.50(1.30-1.73)$ & Up & $6.12 \mathrm{E}-06$ \\
\hline
\end{tabular}

$\mathrm{FC}=$ fold change, $\mathrm{Cl}=$ confidence interval, $\mathrm{Dir}=$ direction of change, relative to $\mathrm{WT}, \mathrm{GKO}=$ GPR54 knockout, $\mathrm{KKO}=$ Kisspeptin knockout. tables in Additional file 8). We further considered only changes of $>1.5$ fold.

The greatest transcript level regulation was observed for Kiss1 (Tables 1, 4), measured in GKO mice which showed strong hormonal regulation (approximately 12 fold down-regulated with $\mathrm{T}$ ) and moderate genotype dependence (approximately 2 fold up-regulated in the GKO animals). With the $18 \mathrm{~S}$ rRNA loading control, the regulation shows a weak interaction whereas with the Gapdh loading control, hormonal regulation, and genotype regulation vary symmetrically and thus no interaction is reported. The hormonal effect of Kiss 1 expression in the male mouse has already been shown [22], here, we validated the Kiss1 up-regulation in hormonally untreated intact male GKO mice by IHC using a kisspeptin antibody that has been previously characterised by our group and others [20]. Kisspeptin immunoreactivity was examined in coronal sections of the regions containing the anteroventral periventricular nucleus (AVPV) and the arcuate nucleus (ARC) from four WT and four GKO adult male mice (Figure 2). In terms of kisspeptin fiber distribution, fibers were found in large numbers in the ARC in both WT and GKO mice, and with virtually no cell bodies observed in the AVPV region. Kisspeptin neuron cell bodies, observed by an intense staining in the dorsal part of the ARC, are significantly more abundant in the GKO ARC than the WT ARC $(p<0.01)$. Kisspeptin fibers have a similar intensity between the two groups. Although kisspeptin immunoreactivity is modest in the AVPV region, we found more kisspeptin fibers in GKO than WT in this region $(p<0.05)$.

The second largest effects were found for the Klk1b22 gene (also known as $\beta$-NGF-endopeptidase) showing a significant hormonal influence (Tables 2, 5) and 3-4 fold regulation. As expected, the GnRH receptor (Gnrhr) also exhibited strong hormonal regulation and a weak genotype effect but with some interaction (the hormone effect is relatively stronger in the KO than the WT mice, compatible with a priming effect), however with large variances of expression.

In KKO mice, only Gnrhr showed a pure hormonal regulation of its transcript and only Tmem144 showed a purely genotype-dependent regulation. The latter was consistent in direction and magnitude with the levels measured in the non-castrate group of animals used for discovery (Table 1), emphasizing this to be a robust difference. Among the genotype and hormone variant changes, Klk1b22 showed the greatest differences, more than 4 fold, with testosterone exposure and this effect was significantly greater $(\mathrm{p}<0.05)$ in the knockout mice (both alleles) than wild-type.

In GKO mice, Klk1b22 showed a hormone only effect (down-regulation) with the Gapdh control, but a 
Table 4 Genes showing hormonal and genotype transcriptional differences, but without co-dependence

\begin{tabular}{ccccccc}
\hline & & \multicolumn{2}{c}{ Genotype Effect } & \multicolumn{2}{c}{ Hormonal Effect } \\
\hline Genotype & Gene Target & FC (95\%Cl) & Direction & FC (95\%Cl) & Direction & $\boldsymbol{p}$-value \\
\hline GKO & Abca8a & $1.35(1.15-1.58)$ & Down & $1.58(1.35-1.85)$ & Down & $1.39 \mathrm{E}-07$ \\
GKO & Ddx3y & $1.52(1.31-1.77)$ & Down & $1.21(1.04-1.40)$ & Down & $1.52 \mathrm{E}-05$ \\
GKO & Kiss1 & $1.96(1.64-2.35)$ & Up & $12.15(10.15-14.55)$ & Down & $4.29 \mathrm{E}-46$ \\
GKO & Tmem144 & $1.86(1.60-2.16)$ & Down & $1.28(1.10-1.48)$ & Down & $1.51 \mathrm{E}-10$ \\
KKO & Abca8a & $1.21(1.06-1.37)$ & Up & $1.64(1.45-1.86)$ & Down & $1.75 \mathrm{E}-09$ \\
\hline
\end{tabular}

$\mathrm{FC}=$ fold change, $\mathrm{Cl}=$ confidence interval, $\mathrm{Dir}=$ direction of change relative to $\mathrm{WT}$ (genotype panel) and $\mathrm{T}$ (hormone panel). GKO = GPR54 knockout, $\mathrm{KKO}=$ Kisspeptin knockout

hormone effect with genotype interaction using the $18 \mathrm{~S}$ rRNA loading control. Gnrhr shows a strong hormonal effect with a genotype interaction - down-regulation in the wild-type mice and up-regulation in the knockout mice in the presence of testosterone. Tmem144 shows a strong genotype effect in the GKO mice (down-regulated where Kiss1 is overexpressed), but in the opposite direction to KKO mice (up-regulated in the absence of Kiss1), and with an additional marginal hormone effect. We confirmed that Tmem144 is significantly up-regulated in the KKO hypothalamus of the intact male mouse as compared to WT by RNA in situ hybridization $(p<0.001$, Additional file 9). Both KKO and WT antisense probes had significantly more intense staining as compared to their respective sense probe control $(p<$ 0.001 ), and there was not a significant difference between the two control sense probes $(p=0.632)$.

To determine whether the up-regulation of the Tmem144 gene expression in KKO mice observed by
RT-PCR and in situ hybridization existed at the protein level, we performed a series of western blot experiments (Additional file 10). Hypothalami dissected from WT and KKO intact male mice were separated into the anterior and posterior halves. Immunoblot analysis with an anti-TMEM144 antibody revealed a band at the expected size of $39 \mathrm{kDa}$, and other non-specific bands at various sizes. Quantification of TMEM144 protein levels (band at $39 \mathrm{kDa}$ ), by normalizing with $\beta$-tubulin protein levels, showed significantly higher TMEM144 protein levels in KKO anterior hypothalamus compared to WT ( $p=0.034$, Student's t-test). In the posterior hypothalamus, TMEM144 protein levels were higher in KKO than WT, although not significantly $(p=0.131)$.

Genotype only effects were seen in GKO mice at $>1.5$ fold but less than 2 fold for ER $\beta$ (Esr2), Hhip, Lhcgr, and Npas4. We also noticed several matrix metalloproteinase (MMP) family members ( $M m p 2, \quad M m p$, Mmp28) showing mixed hormonal and genotype effects,

Table 5 Genes showing hormonal and genotype transcriptional differences, with co-dependence

\begin{tabular}{|c|c|c|c|c|c|c|c|c|c|c|}
\hline \multirow[b]{3}{*}{ Genotype } & \multirow[b]{3}{*}{ Gene } & \multicolumn{4}{|c|}{ Genotype Effect within Hormonal Group } & \multicolumn{4}{|c|}{ Hormonal Effect within Genotype } & \multirow[b]{3}{*}{$p$-value } \\
\hline & & \multicolumn{2}{|c|}{ No testosterone } & \multicolumn{2}{|c|}{ Testosterone } & \multicolumn{2}{|c|}{ Wild-type } & \multicolumn{2}{|l|}{ Knockout } & \\
\hline & & FC $(95 \% \mathrm{Cl})$ & Dir & FC $(95 \% \mathrm{Cl})$ & Dir & FC $(95 \% \mathrm{Cl})$ & Dir & FC $(95 \% \mathrm{Cl})$ & Dir & \\
\hline GKO & Acsm3 & $1.26(1.01-1.57)$ & Up & $2.28(1.84-2.83)$ & Down & $1.93(1.54-2.42)$ & Up & $1.49(1.21-1.84)$ & Down & $2.02 \mathrm{E}-08$ \\
\hline GKO & $\operatorname{Ar}$ & 1.23(1.09-1.38) & Down & $1.56(1.39-1.75)$ & Down & $1.13(1.01-1.27)$ & Up & $1.12(1.00-1.25)$ & Down & $1.02 \mathrm{E}-08$ \\
\hline GKO & Esri & $1.08(0.96-1.21)$ & Down & $1.31(1.17-1.47)$ & Down & $1.28(1.14-1.43)$ & Down & $1.55(1.39-1.74)$ & Down & $1.36 \mathrm{E}-11$ \\
\hline GKO & Gnrhr & $1.28(0.78-2.12)$ & Down & $3.20(1.70-6.03)$ & Up & $2.29(1.37-3.82)$ & Down & $1.80(0.96-3.35)$ & Up & $1.80 \mathrm{E}-03$ \\
\hline GKO & Kiss1 & $1.95(1.58-2.42)$ & Up & $1.09(0.88-1.35)$ & Up & $9.12(7.36-11.29)$ & Down & $16.34(13.19-20.23)$ & Down & $5.71 \mathrm{E}-52$ \\
\hline GKO & KIk1b22 & $1.25(0.71-2.20)$ & Up & $2.70(1.61-4.52)$ & Down & 1.08(0.61-1.91) & Down & $3.65(2.17-6.12)$ & Down & 0.0004 \\
\hline GKO & Mmp9 & $1.11(0.91-1.35)$ & Up & $1.70(1.40-2.07)$ & Up & $1.11(0.92-1.35)$ & Up & $1.71(1.41-2.08)$ & Up & 2.69E-07 \\
\hline GKO & Six 2 & 1.05(0.73-1.50) & Down & $2.22(1.55-3.18)$ & Up & $1.78(1.24-2.55)$ & Down & $1.30(0.91-1.87)$ & Up & 0.0022 \\
\hline GKO & Tec & $2.48(1.95-3.14)$ & Down & $1.75(1.38-2.22)$ & Down & $1.63(1.29-2.07)$ & Down & $1.16(0.91-1.46)$ & Down & 2.03E-13 \\
\hline GKO & Txnip & $1.04(0.80-1.34)$ & Down & $1.81(1.40-2.35)$ & Up & 1.85(1.43-2.39) & Down & $1.02(0.79-1.32)$ & Up & $8.79 \mathrm{E}-05$ \\
\hline $\mathrm{KKO}$ & Acsm3 & $1.23(1.03-1.48)$ & Up & $1.27(1.03-1.56)$ & Down & 1.86(1.53-2.26) & Up & $1.19(0.98-1.45)$ & Up & $9.80 \mathrm{E}-06$ \\
\hline KKO & Klk1b22 & $1.30(0.92-1.84)$ & Down & $4.30(3.01-6.15)$ & Down & $1.34(0.97-1.84)$ & Down & $4.43(3.01-6.51)$ & Down & $1.75 \mathrm{E}-09$ \\
\hline $\mathrm{KKO}$ & Mmp9 & 1.03(0.68-1.56) & Down & $3.75(2.44-5.75)$ & Down & 1.08(0.74-1.59) & Down & $3.93(2.48-6.22)$ & Down & 0.0127 \\
\hline KKO & Six 2 & $1.08(0.84-1.40)$ & Up & $1.99(1.54-2.57)$ & Up & $1.60(1.24-2.07)$ & Down & $1.15(0.89-1.49)$ & Up & $1.14 \mathrm{E}-05$ \\
\hline KKO & $\mathrm{TeC}$ & $1.07(0.86-1.32)$ & Down & $1.72(1.39-2.12)$ & Up & $1.63(1.32-2.02)$ & Down & $1.12(0.91-1.38)$ & Up & $1.82 \mathrm{E}-05$ \\
\hline KKO & Txnip & $1.16(1.00-1.34)$ & Down & $1.22(1.06-1.41)$ & Up & 1.66(1.44-1.92) & Down & $1.18(1.02-1.36)$ & Down & $3.01 \mathrm{E}-08$ \\
\hline
\end{tabular}

$\mathrm{FC}=$ fold change, $\mathrm{Cl}=$ confidence interval, Dir = Direction relative to WT (genotype subpanel) or T (hormone subpanel). GKO = GPR54 knockout, KKO = Kisspeptin knockout. 
A
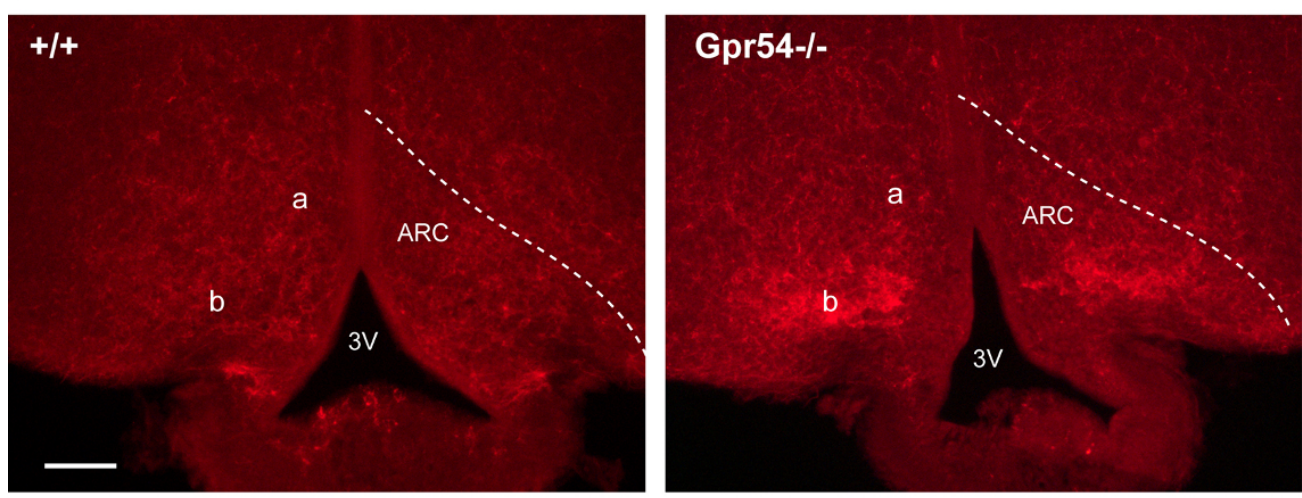

a

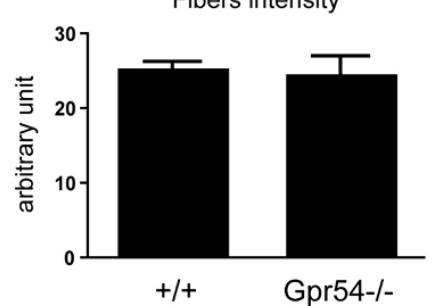

b

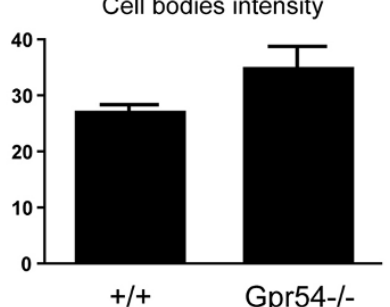

C

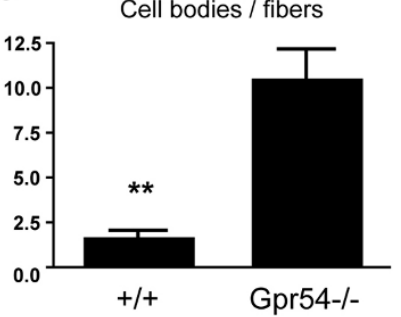

B
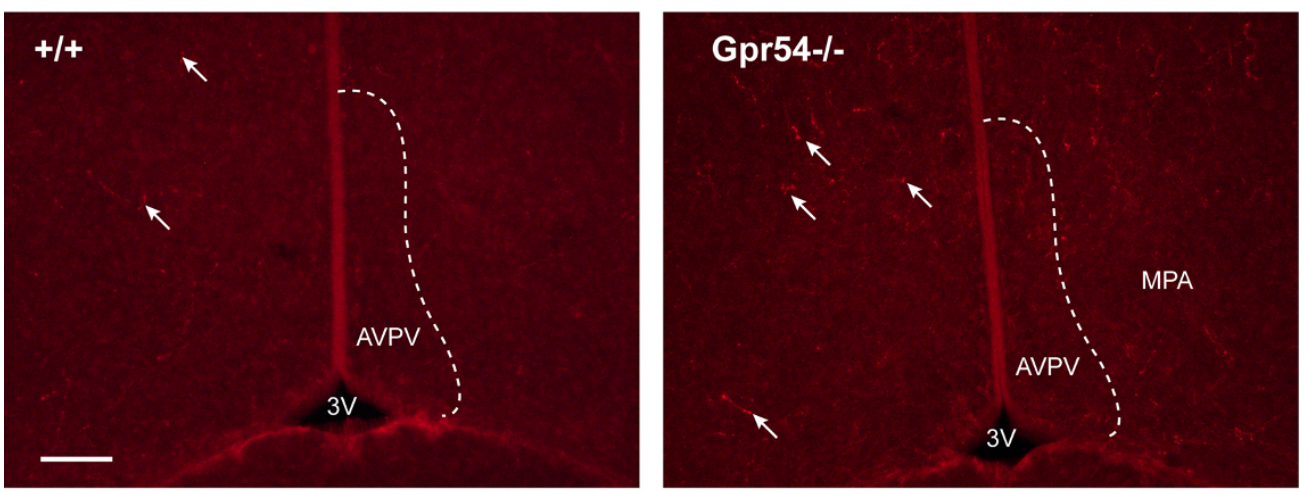

Fibers intensity

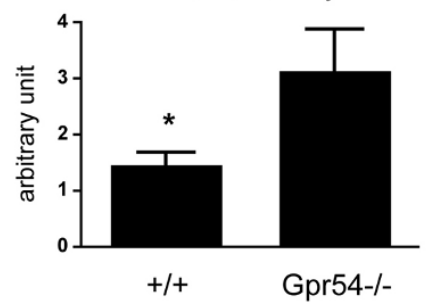

Figure 2 Kisspeptin immunostaining in WT and GKO mice brains. (A) Representative photomicrograph of immunocytochemical staining for kisspeptin (red) in coronal brain sections of the arcuate nucleus (ARC) from wild type (WT) and Gpr54 knockout (GKO) adult male mice.

Bargraphs represent the fiber density in the dorsal ARC (a); the cell body density (b); and the ratio of cell body intensity/fiber intensity ( $c=b / a)$. Note the significantly higher cell body/fiber ratio in the GKO brain. (B) Immunocytochemical staining for kisspeptin (red) in coronal brain sections of the anteroventral periventricular nucleus (AVPV). Arrows indicate kisspeptin-positive fibers in the AVPV and in the medial preoptic area (MPA). The bargraph at the bottom represents density of fibers calculated in the AVPV. ${ }^{*} p<0.05,{ }^{*} p<0.01$, unpaired t-test. $3 \mathrm{~V}$ : third ventricle. Scale bar: $200 \mu \mathrm{m}$. 
but for $M m p 2$ at a fold change less than 1.5. Mmp2 was down-regulated by 1.4 fold in the GKO mice compared to WT and had an independent hormonal effect shown by a 1.2 fold decrease in gene expression when testosterone treatment was compared to the empty silastic control. Mmp28 had a genotype only effect in the GKO mice and was down-regulated by 1.5 fold when compared to WT (Additional file 8: Table S10). We did not analyze in a joint statistical comparison the GKO and KKO transcript variations from the discovery experiment with the GKO T- and KKO T- animals of the validation experiment, because they are not biologically equivalent (see discussion), since the immature testis may be a source of feedback regulation to the hypothalamus.

Npas4, which has very recently been described [24] as an important activity-dependent transcription factor regulating inhibitory synapse formation in the GABAergic system, was up-regulated in GKO mice and was the only novel transcript for which IHC grade antibodies were readily available (generous gift of Michael Greenberg). The NPAS4 protein was expressed in cortical cell bodies of WT (44/hpf - 40× high power field) and GKO (26/hpf) mice (Figure 3C,D). NPAS4 immunoreactivity (ir) was also seen in the hippocampus $(6 / \mathrm{hpf}$ ) (Figure $3 \mathrm{~A}, \mathrm{~B})$, posterior hypothalamus (Figure 3E,F) (11/hpf) and periventricular hypothalamus (7/hpf) (Figure $3 \mathrm{G}$ ) of GKO mice whereas no NPAS4 ir was detectable in WT for any of these regions (0/field) mice. As previously described, we used the Gpr54 driven beta-galactosidase activity (Figure 3, blue neuronal cell bodies) to examine co-localisation of Gpr54 and NPAS4, however none of the cell bodies overlapped in expression, indicating that the alteration of Npas4 expression in GKO mice is non cell-autonomous with respect to Gpr54.

\section{Discussion}

We have assessed gene expression variability amongst Kiss1 and Gpr54 knockout mice (KKO, GKO) to determine potential gene candidates involved in either direct or indirect regulation of this ligand-receptor pair. Initially an Affymetrix Exon 1.0 ST Array consisting of more than 1 million probe sets (exons) was used to find gene expression differences between the genotypes and littermate wild-type mice. Initial array analysis indicated that while there were many overlapping transcription differences between the alleles, some differences were noted. Putative network analysis showed apparently common nodes in HNF4a and some growth factor pathways, however non-overlap was seen in other nodes. Moreover fewer statistically significant expression differences were noted in the Kiss 1 knockout mice. We re-validated these transcriptional differences, using QPCR with quenching probes and using two loading control probes. This yielded a set of 72 genes with confirmed transcriptional differences between genotypes, which were supplemented with an additional 23 genes of interest and controls. Since the knockout mice fail to undergo puberty, it was necessary to separate transcripts that may be subject to hormonal regulation, from those that are independent of hormonal regulation. In a second series of experiments we assessed the expression of the 72 array-derived gene panel and 23 genes of interest, in the hypothalamus of castrated mice, treated with or without hormonal implants prior to gene expression comparisons between genotypes. The comparison of $\mathrm{T}+, \mathrm{T}$-, and genotype groups within the linear mixed effects model analysis allowed us to observe genotype-dependent variation of hormonal response and genotype-independent hormonal response.

Around $500 \mathrm{GnRH}$ expressing neurons are present in the mouse hypothalamus [25,26]. Considering the results of the testosterone/genotype experiment, the detection of significant changes in Gnrhr and Kiss1 transcripts indicates that the relevant region of the hypothalamus was sampled and that the method used was capable of picking up transcriptional differences in two genes known to be hormonally regulated. Our data show for the first time, counter regulation of Kiss1 transcripts and protein expression in Gpr54 knockout mice. This is consistent with previous reports showing that upon interruption of the hypothalamic-pituitary-gonadal axis, Kiss 1 is elevated in the hypothalamus of rodents $[8,22,27]$, primates [28] and women [29].

It has been established that the anteroventral periventricular nucleus (AVPV) and the arcuate nucleus (ARC) are the key regions in the rodent hypothalamus involved in Kiss1 expression [17-19,21,22,30]. We show here for the first time that kisspeptin expression in male $\mathrm{GKO}$ mice is localized to the cell bodies in the ARC and absent in the AVPV. This is in accordance with the sexual dimorphism in kisspeptin expression whereby males have far fewer kisspeptin neurons in the AVPV region than females [30]. Additionally, the kisspeptin neuron cell bodies are significantly more abundant in the GKO ARC than the WT while kisspeptin fibers have a similar intensity between the two groups. Although kisspeptin staining was modest in the AVPV region, we found more kisspeptin fibers in GKO than WT. Thus, the upregulation in Kiss1 gene expression in the hypothalamus observed by RT-PCR using the whole hypothalamus actually occurs in the ARC only since there were no more kisspeptin cell bodies observed in the AVPV from GKO compared to WT mice.

Small differences, although statistically significant, should be interpreted with caution and considering the degree of variation seen with the loading control estimates for the samples, we did not consider absolute 


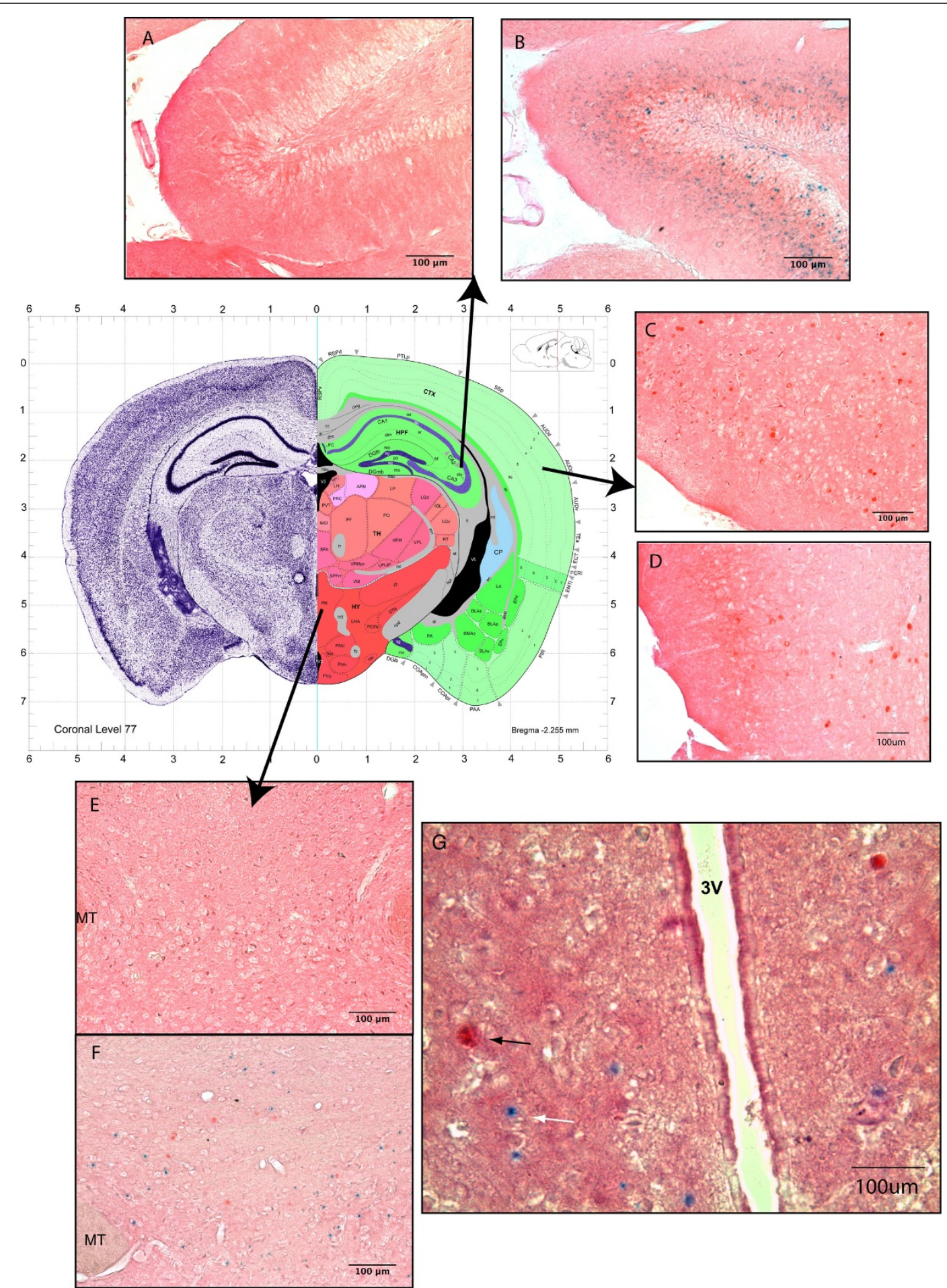

Figure 3 Localization of NPAS4 in the brain of WT and Gpr54 -/- mice. For clarity the brain regions represented in panels A-F are shown mapped to an equivalent coronal section of the Allen brain atlas, corresponding to coronal level 77 (http://mouse.brain-map.org). The conceptual nuclear organization is shown in the right half of the panel, annotations are available at the brain atlas website. (A) WT mouse hippocampus stained with NPAS4 antibody (B) Gpr54 knockout (GKO) hippocampus stained with beta gal (blue cell bodies) and NPAS4 (redbrown). (C) WT cortex stained with NPAS4 antibody (red-brown) (D) GKO cortex stained with beta-gal (blue) for Gpr54 transcription and NPAS4 protein (red-brown) (E) WT posterior hypothalamus stained with NPAS4 antibody (red-brown) (F) GKO posterior hypothalamus stained with beta gal (blue) for Gpr54 transcription and NPAS4 protein (red-brown). (G) a more anterior coronal section (level 71, map not shown here) in GKO showing GPR54 transcription (blue, beta gal) and NPAS4 immunoreactivity in the periventricular hypothalamus. No endogenous beta-gal activity was seen in the wild-type mice in any of the brain regions. MT: mammilothalamic tract. $3 \mathrm{~V}$ : third ventricle. 
effects of less than 1.5 fold to be interpretable, even if statistically significant. It should also be noted that especially where interaction effects are seen, genotype and hormone interaction effects may depend upon differences in the hormonal milieu prior to castration, that may have occurred during development and this limitation should be recognized in generalizing the results. For example, regulation of GnRH receptor levels may show a "priming" effect in wild-type castrate mice from prior perinatal sex steroid exposure, compared with knockouts. The reversed direction of hormonal effect for Gnrhr between GKO and WT is consistent with such an explanation [31]. As we were able to observe robust regulation of Gnrhr, which is predominantly restricted to the 500 or so $\mathrm{GnRH}$ expressing neurons in the mouse hypothalamus, this suggests that the study was powered sufficiently to reveal significant commonalities and differences in the transcriptional networks of Gpr54 and Kiss1 knockout mice.

Interestingly, relatively few large differences in transcription were seen in the initial Affymetrix array experiment, and overall, fewer changes were seen in the Kiss 1 knockout mice, than in the Gpr54 knockout mice. The subsequent detailed QPCR analysis showed this result to be reproducible. Although both genotypes fail to undergo puberty, it has been reported that the kisspeptin loss of function alleles may be less severe than the Gpr54 knockout mice [32]. The endogenous basal activity of the GPR54 receptor could explain such a difference [33] as could the existence of an unknown weaker binding peptide ligand for GPR54. This result is of importance for future studies directed at understanding the signaling consequences of GPR54 and kisspeptin activity.

We did not compare directly the control group of castrate $-\mathrm{T}$ mice with the intact knockout mice. Although the intact knockout mice are also sexually immature, the intact immature testis may still have active feedback to the hypothalamus and transcription differences would be expected. Indeed, a greater difference in Kiss 1 expression was seen in the intact GKO mice than the castrate GKO mice. This is consistent with reports showing that Kiss 1 expression is up-regulated in the hypothalamus of castrated rodents $[12,22]$. We also noticed opposite direction of regulation for the genotype-only transcripts (i.e. for transcripts where $\mathrm{T}$ exposure had no effect) Npas4 and Abca8a between the first and second groups.

The proteolytic pre-processing enzymes responsible for generating active kisspeptins in the hypothalamus are unknown. It has been shown that Kp can down-regulate MMP9 expression [34]. We observed that $M m p 9$ is up-regulated when there is Kiss 1 loss in the KKO mice and the expected down-regulation is observed when there is gain of Kiss 1 expression, as we see in the
GKO mice, however these observations are specific to the hormonally treated group for both mutants. Similarly MMP2 has been shown to be down-regulated by $\mathrm{Kp}$ [35] and in our study $M m p 2$ is down-regulated in the highly expressing Kiss1 GKO mice, although at a fold change less than 1.5. Additionally, reciprocal upregulation is absent in the $\mathrm{KKO}$ mice. Although it has been demonstrated that MMP9/2 can cleave and inactivate $K p$, the precise relationship between the MMPs and $\mathrm{Kp}$ remains to be elucidated. $M m p 28$ exhibited a 1.5 fold genotype only regulation, suggesting it as another potential regulator of kisspeptin. Although all the MMPs were consistent in showing statistically significant transcription changes in our analysis, the extent of regulation was less than 1.5 fold for $M m p 2$ and hence these results should be interpreted with caution.

Beyond the matrix metalloproteases, we observed $K l k 1 b 22$ to be strongly regulated in the KKO and GKO mice. Klk1b22, also known as $\beta$-nerve growth factor (NGF)-endopeptidase [36] is a member of the kallikrein gene cluster that has been expanded by tandem gene duplication. The predicted activity pattern for $K l k 1 b 22$ is cleavage at Arg-Ser residues, an arrangement found within mouse pre-pro kisspeptin that would result in a 52 amino acid peptide, similar to the Kp54 seen in humans. However, $K l k 1 b 22$ does not have an ortholog in the human genome, although several very close paralogs exist in the duplicated kallikreins. The peptide cleavage sequence is not conserved in the human pre-pro kisspeptin, rather, the bond that is cleaved in the human sequence is Arg-Gly to create the N-terminus of Kp-54 $[37,38]$. Our data nevertheless suggest that this kallikrein family of peptidases is worthy of future exploration as kisspeptin processing enzymes, especially since we show strong evidence of regulation in response to sex steroids.

Tmem144 was the only transcript that was consistently up-regulated in the KKO mice as compared with WT mice, independent of testosterone exposure and in all groups of KKO mice. We confirmed this up-regulation by RNA in situ hybridization and western blot analysis of TMEM144 in the hypothalamus of KKO mice as compared to WT mice. Tmem144 encodes an orphan 10-transmembrane family receptor, whose solutes and activities are unknown. This class of transmembrane proteins can transport a wide variety of molecules, ranging from sugars and amino acids to solutes and are generally linked to $\mathrm{Ca}^{2+}$ mediated activation of gene expression. Activation of non-selective cation channels and inhibition of inwardly rectifying potassium channels have been shown to be necessary for $\mathrm{Kp}$ to depolarize GnRH neurons $[39,40]$. It is possible that TMEM144 is somehow implicated in the regulation of kisspeptin expression, its expression was high in the KKO mice lacking Kiss 1 transcripts and low in the GKO mice 
where Kiss1 is over-expressed, suggestive of a direct or indirect negative regulator of kisspeptin. Future genetic studies of Tmem144 will be required to evaluate this possibility.

The transcription factor gene Npas4 was up-regulated in the GKO mice with one of the largest fold changes after the Kiss 1 transcripts yet was down-regulated by 1.7 fold in castrated mice independent of hormonal feedback. This up-regulation in non-castrated mice was confirmed by IHC showing expression of Npas4 in the hypothalamus of Gpr54-/- mice while Npas4 expression was mostly absent in the wild-type mice. Npas 4 has been credited with regulating the development of inhibitory synapses in activating neurons in the hippocampus [24]. Interestingly, Npas4 is activated by an influx of calcium [24] and is independent of the MAP kinase pathway [41]. It has been recently reported that Kp-GPR54 signaling in the hypothalamus of rats is also independent of the MAP kinase pathway but can signal with calcium release [39]. Whether the Npas4 regulation is direct or an indirect consequence of sexual immaturity, remains to be seen, but its role in calcium dependent activation taken together with our data suggest it may play a role in the gonadotropic axis.

Estrogen receptor alpha (Esr1) expression was higher in both GKO and KKO mice compared to sexually mature wild-type males which probably reflects the absence of negative feedback by testosterone in the mutant mice. Consistent with this, Esr1 expression was decreased by 1.2 fold in the castrated KKO mice that were give testosterone implants. In contrast, expression of the estrogen receptor beta (Esr2) was 1.6 fold lower in the GKO mice independent of testosterone effects. Esr2 function in the hypothalamic-pituitary-gonadal axis is currently unknown as hormonal feedback occurs almost entirely through the estrogen receptor alpha $[17,19,22]$ as supported in our study. This is the first report that Esr 2 may be regulated by Kp and GPR54.

Previous studies have identified genes that show an upregulation in the hypothalamus during mammalian puberty including Eap1 (enhanced at puberty 1) [42], Oct2 [43] and Ttf1 (thyroid transcription factor 1) [44]. The role of these genes as key regulators of pubertal initiation is not clear however. Disruption of expression of these genes in the hypothalamus delays but does not prevent entry into puberty in contrast to loss of $\mathrm{Kp} / \mathrm{Gpr} 54$ signaling which is associated with complete loss of puberty. We did not observe any difference in expression of these genes in our analysis suggesting that they may only facilitate puberty rather than act as essential regulators.

\section{Conclusions}

Taken together our results reveal for the first time, using a genome-wide discovery approach, the complex network of gene regulation that is dependent on GPR54 and kisspeptin. We have identified from this network, transcripts whose regulation is strongly dependent on sex-steroid exposure and therefore likely to be a secondary consequence of sexual immaturity in these mutants. Importantly, we have also identified novel transcripts, such as Tmem144 whose regulation is independent of sex steroid exposure and are therefore prime candidates for direct involvement in the biology of kisspeptin and GPR54 regulation. Future genetic and biochemical studies will determine the role of these genes in the gonadotropic axis.

\section{Methods}

\section{Experimental design}

Part i) To discover novel gene candidates that may be involved in the Kp-GPR54 signaling pathway, we assessed gene expression differences in the hypothalamus of Kiss1 and Gpr54 knockout mice (KKO, GKO) compared to wild-type mice (WT). Affymetrix Exon 1.0 ST Arrays sampling approximately 1 million exons, were used to assess gene expression initially. After analysis of the exon array probesets, differentially expressed transcripts were re-validated using QPCR with 384-well low density array (LDA) plates, assayed in an ABI 7900 HT real-time PCR device.

Part ii) To account for hormonally regulated transcripts that may be differentially regulated as a consequence of sexual immaturity in the mutant mice yet not directly affected by Kp/GPR54 signaling, a hormonally controlled group of mice were assessed. To ensure equal hormone exposure in all genotypes (GKO, KKO, WT), all mice were castrated prior to treatment. Treatment consisted of either a testosterone implant or an empty silastic control. The hypothalamus was again isolated for assessment of differential gene expression, this time using a smaller QPCR array of 48 genes.

\section{Animals}

Gpr54 and Kiss1 knockout mice have been previously described [2,10,23]. Male 129S6/Sv/Ev wildtype, 129S6/ Sv/Ev Gpr54- or 129S6/Sv/Ev Kiss1- knockout mice were housed under conditions of 12 hours of light with ad libitum access to food and water. The average age of the mice from the first analysis was 60-70 days and 90 days for the second hormonally controlled group. All experimental protocols were performed under the authority of a United Kingdom Home Office Project License and were approved by the Cambridge Animal Ethics Committee.

\section{Castration and testosterone implants}

Adult males were bilaterally castrated under general anaesthesia using Ketamin/Xylasine. Castrated mice 
were divided into two groups: bilateral castration plus empty implant or bilateral castration plus testosterone implant. Testosterone implants were manually and aseptically prepared in the laboratory using silicone tubing (0.058 inch ID/0.077 inch OD; Dow Corning) filled with crystalline testosterone (T-1500; Sigma Aldrich, UK), and sealed with adhesive silicone type A glue [45]. Implants were inserted subcutaneously at the time of castration. Mice were allowed approximately $3-4$ weeks for recovery (the first week with paracetamol in the water supply), and killed by $\mathrm{CO}_{2}$ exposure. Blood was collected in a heparinized syringe from the inferior vena cava and centrifuged at $1,000 \times \mathrm{g}$ for $10 \mathrm{~min}$ at $4{ }^{\circ} \mathrm{C}$. The plasma supernatant samples were collected and stored at $-20^{\circ} \mathrm{C}$. The mice characteristics are listed in Additional file 7: Table S4.

\section{Testosterone assay}

Free testosterone was measured in duplicate using an ELISA kit (DB52181; IBL, Hamburg, Germany) with a sensitivity of $0.17 \mathrm{pg} / \mathrm{ml}$ and intra- and inter-assay variation coefficients respectively $8.9 \%$ and $8.8 \%$ [23].

\section{Hypothalamus dissection for RNA extraction}

After removal of the brain, the meninges and optic chiasm were discarded and the hypothalamus was isolated. The external limits for this dissection were: lateral, the external border of the medial preoptic area and more caudally, the lateral borders of the mammillary nucleus; dorsal, $1.5 \mathrm{~mm}$ depth; anterior, the anterior limit of the nucleus of the vertical limb of the diagonal band (bregma $+1.34 \mathrm{~mm}$ ); and posterior, the posterior limit of the mammillary nucleus (bregma $-3.40 \mathrm{~mm}$ ). The whole hypothalamus contained at least the following main hypothalamic nuclei: arcuate nucleus (ARC), anteroventral periventricular nucleus (AVPV), anterodorsal preoptic nucleus (ADP), magnocellular nucleus (MA), supraoptic (SON) and paraventricular (PVN) nuclei, medial preoptic area (MPO) and the diagonal band of Broca (DBB). Immediately after dissection, hypothalami samples were placed in $600 \mu \mathrm{l}$ of RNAlater (Applied Biosystems, UK) and kept at $4^{\circ} \mathrm{C}$ for $24 \mathrm{~h}$ and then stored at $-20^{\circ} \mathrm{C}$ until RNA extraction.

\section{RNA extraction}

RNA was extracted using the Qiazol method (Invitrogen, Carlsbad, CA) that is recommended for fatty tissues. Whole hypothalami were removed from RNAlater, with excess reagent blotted off of the tissue with a kimwipe before being placed in 100-200 $\mu \mathrm{l}$ of Qiazol. The hypothalami were then homogenized using a Kontes Pellet Pestle (Fischer Scientific, Ottawa, ON) hand-held homogenizer until a uniform mixture was achieved. The remaining Qiazol up to $1 \mathrm{ml}$ was added to the homogenized mixture and the total homogenate was placed in a phase lock tube to separate out the aqueous phase through centrifugation. RNA was precipitated out of the aqueous phase with an equal volume of isopropanol and pelletted by centrifugation. Seventy percent ethanol was used to wash the pellet that was then airdried, resuspended into 5.5-11.5 $\mu \mathrm{l}$ of RNase/DNase free water, and heated to $65^{\circ} \mathrm{C}$ for $10 \mathrm{~min}$. One and a half microliters of RNA was set aside for Agilent analysis and RNA was stored at $-80^{\circ} \mathrm{C}$.

\section{Agilent analysis}

RNA concentration and integrity (RIN) were determined by the Agilent 2100 bioanalyzer as per manufacturer's recommendations. Briefly, $1 \mu \mathrm{l}$ of heat denatured RNA mixed with $5 \mu \mathrm{l}$ of Nano Marker was run on a RNA 6000 NanoChip (Agilent Technologies, Mississauga, $\mathrm{ON}$ ) already prepared with prefiltered Nano gel matrix mixed with Nano dye concentrate. RNA samples were compared to $1 \mu \mathrm{l}$ of NanoChip RNA 6000 ladder.

\section{Affymetrix procedure}

Hypothalamic RNA was purified further using the GeneChip Whole Transcript Sense Target Labeling Assay (Affymetrix, Santa Clara, CA) as per manufacturer's recommendations before being hybridized to a GeneChip Mouse Exon 1.0 ST Array (Affymetrix, Santa Clara, CA). One microgram of RNA was used as starting material with all samples having a RIN ranging between 8.2-9.0. Starting RNA was mixed with Control Poly-ARNA before using the RiboMinus Transcriptome Isolation Kit (Invitrogen, Carlsbad, CA) as per Affymetrix recommendations to reduce the rRNA contamination within the sample. Each batch of RNA run through the RiboMinus kit was run in parallel with mouse liver RNA that had either been rRNA reduced or left unreduced as a comparison for effectiveness of the RiboMinus assay. The rRNA reduced samples and liver controls were then purified and concentrated using the GeneChip In vitro transcription (IVT) cRNA Cleanup Kit and assessed by Agilent analysis. Successfully rRNA reduced samples continued forward to first strand cDNA synthesis using T7-(N)6 primers and SuperScript II enzyme before second strand cDNA synthesis using DNA Polymerase I. Within 10 min of second strand cDNA synthesis, samples were run through the GeneChip Whole Transcript cDNA Amplification Kit before IVT cRNA Cleanup and then assessed for cRNA concentration by NanoDrop analysis (NanoDrop Technologies, Wilmington, DE). Samples with cRNA concentrations equal to or greater than $10 \mu \mathrm{g}$ in a total volume of $6.5 \mu \mathrm{l}$ were carried forward to the second cycle of first-strand cDNA synthesis using the GeneChip Whole Transcript cDNA synthesis Kit. Random primers with a deoxyuridine triphosphate 
(dUTP) component mixed within the deoxynucleotide triphosphates (dNTPs) were used. The single stranded cDNA was then treated with RNase $\mathrm{H}$ to hydrolyze any remaining cRNA and run through the cDNA Cleanup Spin Columns as per the GeneChip Sample Cleanup Module. Eluted cDNA was assessed by NanoDrop for sample concentration. Finally, $5.5 \mu \mathrm{g}$ of single stranded cDNA was fragmented with Uracil DNA Glycosylase (UDG) and APE 1 then labeled with biotin allonamide triphosphate (TdT) using the GeneChip Whole Transcript Terminal Labeling Kit before being hybridized for $17 \mathrm{~h}$ to the Mouse 1.0 ST Array chip in the GeneChip Hybridization Oven 640 using the GeneChip Hybridization, Wash and Stain Kit. Before scanning the chip on the GeneChip Scanner 3000 7G, each chip was run through the GeneChip Fluidics Station 450 for washing and staining with Streptavidin Phycoerythrin (SAPE). When the sample yielded a concentration less than required for subsequent steps in the protocol, the process was started over again and resulting volumes amalgamated (and in some instances vacuum centrifuged to increase the concentration) before moving forward to the next step.

\section{Quantitative real-time polymerase chain reaction (QPCR)} The Applied Biosystems (ABI) 7900HT Fast Real-Time System was used to amplify and detect mouse cDNA transcripts (Applied Biosystems, Foster City, CA). For high throughput detection a Taqman Low Density Array (LDA) Card from ABI consisting of 95 genes including two endogenous control genes (Gapdh and 18S rRNA) was custom ordered. To assess the second group of mice independent of hormonal feedback, a second smaller LDA set was ordered consisting of 48 genes. The gene list was similar to that of the first larger LDA and had the same two endogenous controls. The complete list of genes used for both LDAs are in Additional files 2 and 11 .

\section{Network analysis}

Analysis was conducted using literature-curated data at http://www.ingenuity.com. A data set containing gene identifiers from the GKO and KKO expression arrays and corresponding expression values was uploaded into in the application. Each identifier was mapped to its corresponding object in Ingenuity's Knowledge Base. All expression values passing initial array significance analysis were included and used. These molecules, called Network Eligible molecules, were overlaid onto a global molecular network developed from information contained in Ingenuity's Knowledge Base. Networks of Network Eligible Molecules were then algorithmically generated based on their connectivity. The top 3 canonical networks with more than 3 molecules were merged into a global network for the GKO and KKO genes (Additional files 2 and 4). For clarity each of the three individual networks is also shown separately (Additional file 3).

\section{Kisspeptin Immunohistochemistry (IHC)}

Four WT and four GKO male mice were deeply anesthetized with pentobarbital (400 $\mathrm{mg} / \mathrm{kg}$, i.p.) and perfused transcardially with $20 \mathrm{ml}$ of $4 \%$ paraformaldehyde in $0.1 \mathrm{M}$ phosphate buffer (PB), $\mathrm{pH}$ 7.4. Brains were removed and immersed in the same fixative for 1 $\mathrm{h}$ at $4^{\circ} \mathrm{C}$ and stored in PB until sectioned. $40 \mu \mathrm{m}$ Vibratome (VT1000S; Leica, Wetzlar, Germany) coronal floating sections containing the anteroventral periventricular (AVPV) nucleus and the arcuate nucleus (ARC) regions were incubated for $16 \mathrm{~h}$ at $4{ }^{\circ} \mathrm{C}$ in a polyclonal rabbit anti-kisspeptin-10 antiserum (1:5,000; no. 566, gift from A. Caraty, Tours, France) in Tris-buffered saline (TBS; $0.2 \mathrm{M}$ Tris, $0.15 \mathrm{M}$ sodium chloride) solution containing $0.3 \%$ Triton $\mathrm{X}-100$, and $5 \%$ normal goat serum. Sections were then washed four times in TBS (10 min/wash) and exposed to Alexa Fluor 568-conjugated anti-rabbit antibody (1:500, Invitrogen) for $1 \mathrm{~h}$ at room temperature. After washes, sections were incubated for $5 \mathrm{~min}$ with DAPI $10 \mu \mathrm{g} / \mathrm{ml}$ (D9542, Sigma Aldrich) in TBS for nuclear fluorescent staining, washed with TBS, mounted on polysine glass slides and coverslipped in FluorSave (345789, Merck).

Immunofluorescent labelling images were acquired with a fluorescent system (Axia Imager A1 microscope, AxioCam MRc5 camera, Axiovision software; Zeiss). Alexa 568 positive staining was examined with the FS45 filter set (560-630 nm). For illustration purposes, photomontages were prepared with the help of Photoshop Elements 4.0 and Illustrator CS3 (Adobe Systems).

Analysis was undertaken by using digital images acquired with a $10 \times$ objective. For the kisspeptin staining analysis in the AVPV region, four images were recorded for each animal under the exact same microscope and software settings. Each image was converted to greyscale format and both hemisections were analyzed. In each hemisection, both background (in the medial preoptic area, distal to the third ventricle) and AVPV intensity were considered. The staining intensity was measured using the histogram function in Photoshop Elements 4.0. Specific intensity in the AVPV was calculated by subtracting the background intensity from the AVPV intensity and was expressed in arbitrary unit. Staining analysis in the ARC region was performed as for the AVPV with four images for each animal but we differentiated the kisspeptin fibers (dorsal ARC) from the kisspeptin cell bodies (ventral ARC). In each hemisection, background intensity was measured in the lower left corner of the image to normalize the data. 
Kisspeptin fiber intensity and cell body intensity, in the dorsal and ventral parts of the ARC respectively, were calculated by subtracting the background intensity and were expressed in arbitrary unit. The ratio of cell body intensity/fiber intensity was also calculated. Values for each mouse were used to determine mean counts, and these were used to generate means \pm SEM values for each group. The comparison between each group was subjected to an unpaired Student's t-test.

\section{Hypothalamus dissection for protein extraction}

Four WT and four KKO male mice were killed by $\mathrm{CO}_{2}$ exposure. Brains were removed and the hypothalamus was dissected in two parts: the anterior (AntH) and the posterior hypothalamus (PostH). AntH mainly contains the anteroventral periventricular nucleus (AVPV), the diagonal band of Broca (DBB), the median preoptic nucleus (MnPO), the medial preoptic area (MPA), the medial preoptic nucleus (MPO), and the periventricular nucleus $(\mathrm{PeN})$. PostH mainly contains the arcuate nucleus (ARC), the dorsomedial hypothalamic nucleus $(\mathrm{DMH})$, the lateral hypothalamus (LH), and the ventromedial hypothalamic nucleus (VMH). AntH and PostH tissues were snap frozen in liquid nitrogen and stored at $-80^{\circ} \mathrm{C}$ until protein extraction. Briefly, tissue fragments were dissociated through a $25 \mathrm{G}$ needle in $300 \mu \mathrm{l}$ of lysis buffer ( $\mathrm{pH}$ 7.4, $25 \mathrm{mM}$ Tris, $50 \mathrm{mM} \beta$-glycerophosphate, $1.5 \mathrm{mM}$ EGTA, $0.5 \mathrm{mM}$ EDTA, $1 \mathrm{mM}$ sodium pyrophosphate, $1 \mathrm{mM}$ sodium orthovanadate, Complete protease inhibitors 1X (Roche), $100 \mu \mathrm{g} / \mathrm{ml}$ PMSF, and $1 \%$ Triton X-100. The tissue lysates were cleared by centrifugation at 10,000 g for $15 \mathrm{~min}$ and protein contents were determined using the Bradford method (BioRad). Protein concentration of each sample was adjusted with lysis buffer and one volume of loading buffer $4 \mathrm{X}$ (80 mM Tris- $\mathrm{HCl}, 4 \%$ SDS, $40 \%$ glycerol, $10 \% \beta$-mercaptoethanol, and bromophenol blue, $\mathrm{pH}$ 6.8) was added to 3 volumes of protein lysate. Finally, samples were boiled for $5 \mathrm{~min}$ before storage at $-80^{\circ} \mathrm{C}$ until use.

\section{Western blot analysis}

Samples were re-boiled for $5 \mathrm{~min}$ after thawing and 30 $\mu \mathrm{g}$ of protein per sample were electrophoresed for about $80 \mathrm{~min}$ at $125 \mathrm{~V}$ in $10 \%$ SDS-polyacrylamide gels using a Bio-Rad Mini-Protean system. After size fractionation, the proteins were transferred onto polyvinylidene difluoride $0.45 \mu \mathrm{m}$ pore-size membranes (Immobilion-P, Millipore) using a semi-dry blotting apparatus (Atto, Japan) for $75 \mathrm{~min}$ at room temperature (RT). Blots were blocked for $1 \mathrm{~h}$ in TBS with $0.05 \%$ Tween 20 (TBST) and $5 \%$ non-fat milk at RT, incubated overnight at $4^{\circ} \mathrm{C}$ with a rabbit polyclonal anti-TMEM144 primary antibody (SAB2102456, Sigma) at $1 \mu \mathrm{g} / \mathrm{ml}$ dilution. After incubation with primary antibody, membranes were washed four times with TBST before being exposed to HRP-conjugated secondary anti-rabbit IgG diluted in 5\% non-fat milk TBST for $1 \mathrm{~h}$ at RT. The immunoreactions were revealed with enhanced chemiluminescence (RPN2132, GE Healthcare) and detected with an X-ray film (Konica Minolta). Membranes were then stripped in a stripping solution $(62.5 \mathrm{mM}$ Tris- $\mathrm{HCl}, 2 \% \mathrm{SDS}, \mathrm{pH}$ 6.7, and $100 \mathrm{mM} \beta$-mercaptoethanol) for $30 \mathrm{~min}$ with gentle rocking at $65^{\circ} \mathrm{C}$. Membranes were washed and incubated with HRP-conjugated secondary anti-rabbit IgG antibody was used to verify that all former immunoreactivity was successfully stripped. Membranes were re-probed with a mouse monoclonal anti- $\beta$-tubulin 1:10,000 under the same conditions as described above for the anti-TMEM144 antibody and detected with a HRP-conjugated secondary anti-mouse IgG 1:2000.

Analysis was undertaken by using digital images acquired with a scanner Epson Perfection 1260 and processed by Photoshop Elements 4.0. The intensity of each band for TMEM144 and $\beta$-tubulin was measured using the histogram function in Photoshop and the relative content of TMEM144 was normalized by calculating the ratio TMEM144 intensity/ $\beta$-tubulin for each sample. Values for each mouse were used to determine mean counts, and these were used to generate means \pm SEM values for each group. The comparison between each group was subjected to an unpaired Student's t-test.

\section{NPAS4 immunohistochemistry (IHC)}

Mice (three of each genotype) were perfused with $4.0 \%$ paraformaldehyde/PBS prior to brain dissection, which were then immersed in $20 \%$ sucrose overnight. The brains were frozen in OCT and cryosectioned at 20 microns. Sections were placed onto positively charged slides and kept at $-80^{\circ} \mathrm{C}$. Slides were then hydrated with PBS briefly prior to $\beta$-galactosidase treatment overnight [10]. Slides were washed with PBS then incubated with 4\% paraformaldehyde for 10 minutes, then washed with PBS followed by a $0.03 \%$ hydrogen peroxide treatment for 10 minutes. After a PBS wash slides were incubated with serum-free protein block (Dako) for 2 hours then incubated overnight at $4^{\circ} \mathrm{C}$ with 1:500 NPAS4 antibody generously donated by Michael Greenberg's laboratory [24]. Secondary antibody was 1:100 Goat anti-Rabbit HRP (Dako) for 2 hours. Reactivity was visualized using DAB chromogenic solution, slides were mounted in 50\% PBS and 50\% glycerol and coverslipped. At least two brains were examined for each genotype studied. Microscopy was conducted using a Zeiss Axioscope, with phase contrast.

RNA in situ hybridization (ISH)

The frozen brain sections were prepared as for the NPAS4 IHC except at a thickness of 10 microns for two 
mice of each genotype; WT and KKO. The ISH procedure was based on a protocol developed by Dijkman et al. available through the Roche website (http://www. roche-applied-science.com/PROD_INF/MANUALS/ InSitu/InSi_toc.htm). Specifically, slides were heated at $50^{\circ} \mathrm{C}$ for three minutes and allowed to air dry at RT for 30 minutes. They were then treated with chloroform for 5 minutes and allowed to dry for 5 minutes. The slides were then treated with $4 \%$ paraformaldehyde in PBS for 7 minutes then washed in PBS, followed by washes in 2 $\times$ SSC. The prehybridization step used $100 \mu \mathrm{l}$ of hybridization buffer $(4 \times$ SSC, $10 \%$ dextran sulfate, $1 \mathrm{X}$ Denhardt's solution (Sigma-Aldrich) 2 mM EDTA, 50\% deionized formamide, $500 \mu \mathrm{g} / \mathrm{ml}$ salmon sperm DNA) at $37^{\circ} \mathrm{C}$ for 1 hour. The sense and antisense probes were added to the hybridization buffer at a concentration of $200 \mathrm{ng} / \mathrm{l}$ and slides were incubated with the probes in a humidified chamber overnight at $37^{\circ} \mathrm{C}$.

The probes were created by PCR amplification using cDNA from a WT mouse hypothalami and PCR primers that included the Sp6 and T7 promoter sequences for RNA transcription. The sense primer sequence was ATT TAG GTG ACA CTA TAG ATG AGC AGC AAT GCA ACA GAC and the antisense primer sequence was TAA TAC GAC TCA CTA TAG GGC GTG AGC GCA CTT ACT ACT GA. The PCR product produced the expected single $461 \mathrm{bp}$ band on gel electrophoresis and was Sanger sequenced prior to gel extraction to confirm the correct Tmem144 sequence. The Roche Digoxigenin (DIG) RNA Labeling Kit (SP6/ T7) was used to create the DIG label sense and antisense probes as per manufacturer's recommendation.

After probe hybridization the slides were washed with $2 \times$ SSC followed by a $60 \%$ formamide in $0.2 \times$ SSC wash both at $37^{\circ} \mathrm{C}$. There were final washes with $2 \times$ SSC at RT and with $100 \mathrm{mM}$ Tris- $\mathrm{HCl}, 150 \mathrm{mM} \mathrm{NaCl}$ (pH 7.5) prior to probe detection. The Roche DIG Nucleic Acid Detection Kit (NBT/BCIP) was used to visualize the ISH probes. Specifically, the sections were incubated for 30 minutes at RT with blocking buffer (100 mM Trish- $\mathrm{HCl}, 150 \mathrm{mM} \mathrm{NaCl}$ used to dilute 10X blocking reagent to $1 \mathrm{X}$ ). The alkaline phosphatase-conjugated sheep anti-DIG was diluted to 1:200 in the blocking buffer and used to incubate the slides for 2 hours at RT. After incubation the slides were washed with $100 \mathrm{mM}$ Trish- $\mathrm{HCl}, 150 \mathrm{mM} \mathrm{NaCl}$ and incubated for 10 minutes with detection buffer $(100 \mathrm{nM}$ Tris- $\mathrm{HCl}$, $100 \mathrm{mM} \mathrm{NaCl}, 50 \mathrm{mM} \mathrm{MgCl} 2$ ). Slides were incubated overnight with detection buffer containing $0.18 \mathrm{mg} / \mathrm{ml}$ 5-bromo-4-chloro-3-indolyl-phosphate, $0.34 \mathrm{mg} / \mathrm{ml}$ nitroblue tetrazolium chloride (Roche kit) and $240 \mu \mathrm{g} /$ $\mathrm{ml}$ levamisole at RT. After a distilled water wash the slides were counterstained with $1 \%$ methylene green and mounted in aqueous based media. Microscopy was conducted with an Olympus BX46 light microscope and captured with the Olympus DP21 digital camera.

\section{RNA ISH image analysis and quantification}

Images of tissue sections were analyzed by our in-house image processing package (imQui), which provided an interactive, user-interface to test and setup the processing pipeline as well as the utility to execute the developed pipeline on the set of images. First, each color image was separated into its red, green, and blue components. As the red channel image contained the least noise among the three colors, it was chosen for nuclei segmentation and measurements. The red image was inverted to appear like a fluorescence image, such that previously developed nuclei segmentation algorithms could be used [46]. Background subtraction was employed to compensate for lighting and shading variations in the image. Otsu thresholding and watershed segmentation were then applied to detect and separate any touching nuclei. For each nuclear defined region, the mean intensity of the object (in the red channel image) was evaluated. Finally, the estimated absorbance density for each object was evaluated by subtracting the logarithm of the mean object intensity by the logarithm of the illumination intensity (the same illumination intensity level was used for all images, since the same imaging conditions were applied to all images). Comparison of significance in differences between samples was performed using a two-sided Student's t-test on the optical density values.

\section{Affymetrix and QPCR statistical analysis}

(i) Affymetrix chip data was quantile normalized and corrected using the GC-RMA algorithm [47]. Stratagene ArrayAssist version 5.1.0 was used to analyze the Affymetrix data (located at: http://www.ncbi.nlm.nih.gov/ geo $/$ query $/$ acc.cgi? token $=$ vxytbewkkqaqeze $\&$ acc $=$ GS E28383) and create volcano plots. Experimental groups were compared using unpaired t-tests. Differential expression was analyzed with gene-level and exon level models in ArrayAssist and genes passing the filters (Figure 1) of $>1.5$ fold expression difference and $p<0.05$ after correcting for multiple comparisons were included. Using the volcano plot distributions additional outliers (locally isolated data points, showing large fold change or small $p$-value, Additional file 1) were included. Table $\mathrm{S} 1$ in Additional file 5 lists the characteristics and probe values for the 198 genes passing these criteria.

(ii) QPCR data was analyzed using linear mixed effects models, with experimental groups compared via the likelihood ratio chi-square statistic $[48,49]$. Adjustment for multiple comparisons was performed using the Benjamini-Hochberg method [50]. For the testosterone challenge experiment, a linear mixed effects model was used 
to relate raw $\mathrm{Ct}$ values from loading control genes (Gapdh, 18S rRNA) and test genes.

$$
Y_{i j k l m}=\mu+\delta_{i}+\gamma_{j}+\tau_{k}+\delta \gamma_{i j}+\delta \tau_{i k}+\gamma \tau_{j k}+\delta \gamma \tau_{i j k}+\alpha_{l(j k)}+\varepsilon_{m(i j k l)}(1.1)
$$

$Y_{i j k l m}=$ QPCR cycle time for gene target $\mathrm{i}$, genotype $\mathrm{j}$, hormone condition $\mathrm{k}$, animal $\mathrm{l}(\mathrm{jk})$ and technical replicate $\mathrm{m}(\mathrm{ijkl})$ where;

$\mathrm{i}=1$ (loading control), 2 (gene of interest)

$\mathrm{j}=1$ (WT), 2 (KO)

$\mathrm{k}=1$ (No testosterone in implant), 2 (testosterone in implant)

$\mathrm{l}=1,2, \ldots, \mathrm{n}_{1(\mathrm{jk})}$ indicates mouse number for conditions $\mathrm{j}$ and $\mathrm{k}$

$\mathrm{m}=1,2, \ldots, \mathrm{n}_{\mathrm{m}(\mathrm{ijk})}$ indicates technical replicate for conditions $\mathrm{i}, \mathrm{j}, \mathrm{k}, \mathrm{l}$.

$\mu=$ overall Ct level

$\delta_{i}=$ change in Ct level corresponding to gene target (loading control or gene of interest)

$\gamma_{j}=$ change in Ct level due to genotype

$\tau_{k}=$ change in Ct level due to hormone implant

$\alpha_{l(j k)}=$ random effect on Ct level attributable to the lth animal within conditions $j$ and $k$, arising from a Gaussian distribution with mean 0 and variance $\sigma_{\alpha}$

$\varepsilon_{m(i j k l)}=$ random effect on Ct level due to technical variability, arising from a Gaussian distribution with mean 0 and variance $\sigma_{\varepsilon}$

The remaining terms $\delta \gamma_{i j}, \delta \tau_{i k}$, $\delta \tau_{j k}$ and $\delta \gamma \tau_{i j k}$ represent second and third order interaction terms of the three main effects. Estimates of these parameters obtained from the data via restricted maximum likelihood fitting (REML) will be denoted with a circumflex, for example the estimate of the difference in expression level due to genotype $j \gamma_{j}$ is denoted as $\hat{\gamma}_{j}$.

$\delta \gamma_{i j}$ allows the model to reflect a different expression level in the gene of interest in the $\mathrm{KO}\left(\Delta C_{t}\right.$ in the $\left.\mathrm{KO}\right)$ as compared to that seen in the WT in the placebo implanted animals $\left(\Delta C_{t}\right.$ in the WT). Thus in QPCR terminology $\Delta \Delta C_{t}$ for the placebo implanted animals is estimated by $\delta \gamma_{i j}$

$\delta \gamma \tau_{i j k}$ allows the model to reflect a different expression level in the gene of interest in the $\mathrm{KO}\left(\Delta C_{t}\right.$ in the $\left.\mathrm{KO}\right)$ as compared to that seen in the WT in the testosterone implanted animals $\left(\Delta C_{t}\right.$ in the WT). In QPCR terminology $\Delta \Delta C_{t}$ for the testosterone implanted animals is estimated by $\delta \gamma_{i j}+\delta \gamma \tau_{i j k}$.

$\delta \tau_{i k}$ allows the model reflect a different baseline expression level of the gene of interest in the testosterone implanted animals relative to the placebo implanted animals.

$\gamma \tau_{j k}$ allows the model to reflect a different baseline expression level of the loading control in the knockout animals relative to the wild-type animals.
In the terminology of linear mixed effects models, gene target, genotype and hormone implant factors are fixed effect factors; and animal is a random effects factor. Animal is modeled as a random effect as the animal effect for each animal is not of interest in this experiment. Rather, the results are to be interpreted with respect to the overall mouse population, and the animals included in this experiment represent a random sample from the overall population. The two genotypes, Kiss 1 knockout and Gpr54 knockout, were modeled separately using the model (1.1). Although all factors could have been put in one $2 \times 2 \times 3$ model, for simplicity the data from Kiss 1 and Gpr54 knockouts were modeled separately, in two $2 \times 2 \times 2$ factorial designs (genotype: $w t$ or ko; treatment: $\mathrm{T}-$ or $\mathrm{T}+$; gene: test or loading control). The relationship between the model-estimated means for each of the conditions allowed inference of four effect types of interest. These were: genotype only transcription differences, hormone treatment only transcription differences, hormone and genotype differences where the rate of difference is symmetrical (no interaction between effects), and hormone and genotype differences where the differences between groups show an effect interaction (ie the difference for hormone treatment is disproportionately greater in one genotype). The linear model was fitted using the lmer function from the lme4 package implemented in R-2.7.0 [51,52]. The model output was used to construct estimates of the mean relative effect and direction, 95\% confidence intervals, and omnibus $p$-value (from likelihood-ratio chisquare test of any effect due to genotype or hormone adjusted for multiple corrections by the Benjamini Hochberg method).

\section{Additional material}

Additional file 1: Supplemental Figure 1. Volcano plots from the Affymetrix Exon 1.0 ST Array. Genes that were considered for further analysis are represented by yellow squares. The $x$-axis is the fold change for comparison groups that are indicated on the left side of the figures. The $y$-axis is the $p$-value among biological replicates.

Additional file 2: Supplemental Figure 2. GKO hypothalamic transcription networks merged. The top three networks of GKO hypothalamic transcription merged.

Additional file 3: Supplemental Figure 4. GKO and KKO hypothalamic transcription networks. The top three networks for both GKO and KKO hypothalamic transcription shown separately.

Additional file 4: Supplemental Figure 3. KKO hypothalamic transcription networks merged. The top three networks of KKO hypothalamic transcription merged.

Additional file 5: Supplemental Table 1. The characteristics and probe locations of the outliers from the volcano plots representing the Affymetrix results.

Additional file 6: Supplemental Table 2. Genes carried forward for QPCR validation from initial array analysis. Lists the 95 genes assessed by QPCR that were chosen from the initial array analysis. 
Additional file 7: Supplemental Table 4. Characteristics of the hormonally treated mice. Lists the characteristics of the mice used in the T response cohort.

Additional file 8: Supplemental Tables 5-12. These tables list the complete model results for the four classes of variation for each genotype: (i) purely hormone-dependent transcription (ii) purely genotype-dependent transcription (iii) hormone and genotypedependent transcription but with no interaction between these variables and (iv) hormone and genotype-dependent transcription, with codependence (interaction) between these variables.

Additional file 9: Supplemental Figure 5. Tmem144 in situ hybridization in the hypothalamus of WT and KKO male mice. Tmem144 in situ hybridization in the ARC of the hypothalamus of WT (top) and KKO (bottom) intact male mice (A). The sense probe is used as a negative control and is shown on the left while the antisense probe stains as a dark brown precipitate and is shown on the right. Quantification of the optical density is shown in a bar graph (B) where the asterisk denotes statistical significance between the means. *: $p$ > 0.01. S: sense. AS: antisense. $3 \mathrm{~V}$ : third ventricle. Scale bar represents 100 $\mu \mathrm{m}$.

Additional file 10: Supplemental Figure 6. TMEM144 protein content in the hypothalamus of WT and KKO male mice.

Immunoblotting of anterior hypothalamus (A) or posterior hypothalamus (B) protein lysates showed bands at $39 \mathrm{kDa}$ for TMEM144 and $50 \mathrm{kDa}$ for $\beta$-tubulin. Bargraphs represent the TMEM144 protein levels in the anterior (A) and the posterior hypothalamus (B), and are expressed in arbitrary unit as the mean of the ratio Tmem144/ $\beta$-tubulin in each sample. Note the significantly higher TMEM144 protein expression in the anterior hypothalamus from KKO mice ( ${ }^{*} p=0.034, \mathrm{n}=4$ for each). Individuals are numbered 1 to 8 .

Additional file 11: Supplemental Table 3. Genes carried forward into the T response QPCR analysis. Lists the 48 genes assessed by QPCR using the T response cohort of mice.

\section{Acknowledgements}

We would like to thank Cath Ennis for her assistance and support in preparing the manuscript for submission. The research was supported by: BBSRC Grant BB/F01936X/1.

\section{Author details}

${ }^{1}$ Molecular Oncology and Breast Cancer Program, British Columbia Cancer Research Centre, 675 West 10th Avenue, Vancouver, BC, V5Z 1L3, Canada. ${ }^{2}$ Department of Pathology, University of British Columbia, Vancouver, BC, Canada. ${ }^{3}$ British Columbia Cancer Agency, 600 West 10th Avenue, Vancouver, BC, V5Z 4E6, Canada. ${ }^{4}$ Genetic Pathology Evaluation Centre of the Prostate Centre, Department of Pathology, Vancouver Coastal Health Research Institute, Vancouver, BC, Canada. ${ }^{5}$ Reproductive Physiology Group, Department of Physiology, Development, and Neuroscience, University of Cambridge, Downing Street, Cambridge,CB2 3EG, UK.

\section{Authors' contributions}

LMP performed all experiments except the murine studies, kisspeptin $I H C$, and TMEM144 western blot, drafted the original manuscript, and participated in manuscript editing. XD performed all murine studies except for the mice used in the NPAS4 IHC and Tmem144 ISH analysis, performed the testosterone assay, performed the kisspeptin IHC and TMEM144 western blot, and participated in manuscript editing. SM performed all the statistical analysis for the Affymetrix and real-time PCR and participated in manuscript editing. TR maintained the mouse husbandry and performed the brain extractions for the NPAS4 IHC and Tmem144 ISH studies. DY assisted in establishing the ISH protocol and ISH experiment. GT quantified the IHC expression. SP quantified the ISH expression. MS participated in the murine IHC and ISH studies. PA performed the brain sectioning for the IHC and ISH studies. $A B$ performed the microscopic photography for the $\mathrm{IHC}$ studies. JF participated in the initial experiments. DGH participated in the study design and manuscript editing. SAJA performed the network analysis, and both
SAJA and WHC conceived of the study design and led the manuscript editing. All authors have read and approve of the final manuscript.

Received: 9 August 2010 Accepted: 28 April 2011

Published: 28 April 2011

\section{References}

1. de Roux N, Genin E, Carel JC, Matsuda F, Chaussain JL, Milgrom E: Hypogonadotropic hypogonadism due to loss of function of the KiSS1derived peptide receptor GPR54. Proc Natl Acad Sci USA 2003, 100:10972-10976.

2. Seminara SB, Messager S, Chatzidaki EE, Thresher RR, Acierno JS, Shagoury JK, Bo-Abbas Y, Kuohung W, Schwinof KM, Hendrick AG, Zahn D, Dixon J, Kaiser UB, Slaugenhaupt SA, Gusella JF, O'Rahilly S, Carlton MB, Crowley WF, Aparicio SA, Colledge WH: The GPR54 gene as a regulator of puberty. N Engl J Med 2003, 349:1614-1627.

3. Arreguin-Arevalo JA, Lents CA, Farmerie TA, Nett TM, Clay CM: KiSS-1 peptide induces release of $\mathrm{LH}$ by a direct effect on the hypothalamus of ovariectomized ewes. Anim Reprod Sci 2007, 101:265-275.

4. Castellano JM, Navarro VM, Fernandez-Fernandez R, Castano JP, Malagon MM, Aguilar E, Dieguez C, Magni P, Pinilla L, Tena-Sempere M: Ontogeny and mechanisms of action for the stimulatory effect of kisspeptin on gonadotropin-releasing hormone system of the rat. $\mathrm{Mol}$ Cell Endocrinol 2006, 257-258:75-83.

5. Dhillo WS, Chaudhri OB, Patterson M, Thompson EL, Murphy KG, Badman MK, McGowan BM, Amber V, Patel S, Ghatei MA, Bloom SR: Kisspeptin-54 stimulates the hypothalamicpituitary gonadal axis in human males. J Clin Endocrinol Metab 2005, 90:6609-6615.

6. Dhillo WS, Chaudhri OB, Thompson EL, Murphy KG, Patterson M, Ramachandran R, Nijher GK, Amber V, Kokkinos A, Donaldson M, Ghatei MA, Bloom SR: Kisspeptin-54 stimulates gonadotropin release most potently during the preovulatory phase of the menstrual cycle in women. J Clin Endocrinol Metab 2007, 92:3958-3966.

7. Gottsch ML, Cunningham MJ, Smith JT, Popa SM, Acohido BV, Crowley WF, Seminara SB, Clifton DK, Steiner RA: A role for kisspeptins in the regulation of gonadotropin secretion in the mouse. Endocrinology 2004, 145:4073-4077.

8. Irwig MS, Fraley GS, Smith JT, Acohido BV, Popa SM, Cunningham MJ, Gottsch ML, Clifton DK, Steiner RA: Kisspeptin activation of gonadotropin releasing hormone neurons and regulation of KiSS-1 mRNA in the male rat. Neuroendocrinology 2004, 80:264-272.

9. Matsui H, Takatsu Y, Kumano S, Matsumoto H, Ohtaki T: Peripheral administration of metastin induces marked gonadotropin release and ovulation in the rat. Biochem Biophys Res Commun 2004, 320:383-388.

10. Messager S, Chatzidaki EE, Ma D, Hendrick AG, Zahn D, Dixon J, Thresher RR, Malinge I, Lomet D, Carlton MB, Colledge WH, Caraty A, Aparicio SA: Kisspeptin directly stimulates gonadotropin-releasing hormone release via G protein-coupled receptor 54. Proc Natl Acad Sci USA 2005, 102:1761-1766.

11. Navarro VM, Castellano JM, Fernández-Fernández R, Tovar S, Roa J, Mayen A, Barreiro ML, Casanueva FF, Aguilar E, Dieguez C, Pinilla L, TenaSempere M: Effects of KiSS-1 peptide, the natural ligand of GPR54, on follicle-stimulating hormone secretion in the rat. Endocrinology 2005, 146:1689-1697.

12. Navarro VM, Castellano JM, Fernández-Fernández R, Tovar S, Roa J, Mayen A, Nogueiras R, Vazquez MJ, Barreiro ML, Magni P, Aguilar E, Dieguez C, Pinilla L, Tena-Sempere M: Characterization of the potent luteinizing hormone-releasing activity of KiSS-1 peptide, the natural ligand of GPR54. Endocrinology 2005, 146:156-163.

13. Plant TM: The role of KiSS-1 in the regulation of puberty in higher primates. Eur J Endocrinol 2006, 155(Suppl 1):S11-16.

14. Shahab M, Mastronardi C, Seminara SB, Crowley WF, Ojeda SR, Plant TM: Increased hypothalamic GPR54 signaling: a potential mechanism for initiation of puberty in primates. Proc Natl Acad Sci USA 2005, 102:2129-2134.

15. Thompson EL, Murphy KG, Patterson M, Bewick GA, Stamp GW, Curtis AE, Cooke JH, Jethwa PH, Todd JF, Ghatei MA, Bloom SR: Chronic subcutaneous administration of kisspeptin-54 causes testicular degeneration in adult male rats. Am J Physiol Endocrinol Metab 2006, 291: E1074-1082. 
16. Herbison AE, de Tassigny X, Doran J, Colledge WH: Distribution and postnatal development of Gpr54 gene expression in mouse brain and gonadotropin-releasing hormone neurons. Endocrinology 2010, 151:312-321.

17. Kauffman AS, Gottsch ML, Roa J, Byquist AC, Crown A, Clifton DK, Hoffman GE, Steiner RA, Tena-Sempere M: Sexual differentiation of Kiss1 gene expression in the brain of the rat. Endocrinology 2007, 148:1774-1783

18. Smith JT, Cunningham MJ, Rissman EF, Clifton DK, Steiner RA: Regulation of Kiss 1 gene expression in the brain of the female mouse. Endocrinology 2005, 146:3686-3692

19. Adachi S, Yamada S, Takatsu Y, Matsui H, Kinoshita M, Takase K, Sugiura H, Ohtaki T, Matsumoto H, Uenoyama Y, Tsukamura H, Inoue K, Maeda K. Involvement of anteroventral periventricular metastin/kisspeptin neurons in estrogen positive feedback action on luteinizing hormone release in female rats. J Reprod Dev 2007, 53:367-378.

20. Clarkson J, d'Anglemont de Tassigny X, Moreno AS, Colledge WH, Herbison AE: Kisspeptin-GPR54 signaling is essential for preovulatory gonadotropin-releasing hormone neuron activation and the luteinizing hormone surge. J Neurosci 2008, 28:8691-8697.

21. Kinoshita M, Tsukamura H, Adachi S, Matsui H, Uenoyama Y, Iwata K, Yamada S, Inoue K, Ohtaki T, Matsumoto H, Maeda K: Involvement of central metastin in the regulation of preovulatory luteinizing hormone surge and estrous cyclicity in female rats. Endocrinology 2005, 146:4431-4436

22. Smith JT, Dungan HM, Stoll EA, Gottsch ML, Braun RE, Eacker SM, Clifton DK, Steiner RA: Differential regulation of KiSS-1 mRNA expression by sex steroids in the brain of the male mouse. Endocrinology 2005 , 146:2976-2984

23. d'Anglemont de Tassigny X, Fagg LA, Dixon JP, Day K, Leitch HG, Hendrick AG, Zahn D, Franceschini I, Caraty A, Carlton MB, Aparicio SA, Colledge WH: Hypogonadotropic hypogonadism in mice lacking a functional Kiss1 gene. Proc Natl Acad Sci USA 2007, 104:10714-10719.

24. Lin Y, Bloodgood BL, Hauser JL, Lapan AD, Koon AC, Kim TK, Hu LS, Malik AN, Greenberg ME: Activity-dependent regulation of inhibitory synapse development by Npas4. Nature 2008, 455:1198-1204.

25. Gamble JA, Karunadasa DK, Pape JR, Skynner MJ, Todman MG, Bicknell RJ, Allen JP, Herbison AE: Disruption of ephrin signaling associates with disordered axophilic migration of the gonadotropin-releasing hormone neurons. J Neurosci 2005, 25:3142-3150.

26. $\mathrm{Xu}$ C, Xu XZ, Nunemaker CS, Moenter SM: Dose-dependent switch in response of gonadotropin-releasing hormone $(\mathrm{GnRH})$ neurons to $\mathrm{GnRH}$ mediated through the type I GnRH receptor. Endocrinology 2004, 145:728-735

27. Navarro VM, Castellano JM, Fernández-Fernández R, Barreiro ML, Roa J, Sánchez-Criado JE, Aguilar E, Dieguez C, Pinilla L, Tena-Sempere M: Developmental and hormonally regulated messenger ribonucleic acid expression of KiSS-1 and its putative receptor, GPR54, in rat hypothalamus and potent luteinizing hormone-releasing activity of KiSS1 peptide. Endocrinology 2004, 145:4565-4574

28. Kim W, Jessen HM, Auger AP, Terasawa E: Postmenopausal increase in KiSS-1, GPR54, and luteinizing hormone releasing hormone (LHRH-1) mRNA in the basal hypothalamus of female rhesus monkey. Peptides 2009, 30:103-110.

29. Rometo AM, Krajewski SJ, Voytko ML, Rance NE: Hypertrophy and increased kisspeptin gene expression in the hypothalamic infundibular nucleus of postmenopausal women and ovariectomized monkeys. J Clin Endocrinol Metab 2007, 92:2744-2750.

30. Clarkson J, Herbison AE: Postnatal development of kisspeptin neurons in mouse hypothalamus; sexual dimorphism and projections to gonadotropin-releasing hormone neurons. Endocrinology 2006, 147:5817-5825.

31. Negri-Cesi P, Colciago A, Pravettoni A, Casati L, Conti L, Celotti F: Sexual differentiation of the rodent hypothalamus: hormonal and environmental influences. J Steroid Biochem Mol Biol 2008, 109:294-299.

32. Lapatto R, Pallais JC, Zhang D, Chan YM, Mahan A, Cerrato F, Le WW, Hoffman GE, Seminara SB: Kiss1-/- mice exhibit more variable hypogonadism than Gpr54-/- mice. Endocrinology 2007, 148:4927-4936.

33. Pampillo M, Camuso N, Taylor JE, Szereszewski JM, Ahow MR, Zajac M, Millar RP, Bhattacharya M, Babwah AV: Regulation of GPR54 signaling by GRK2 and \{beta\}-arrestin. Mol Endocrinol 2009, 23:2060-2074.
34. Yan C, Wang H, Boyd DD: KiSS-1 represses 92-kDa type IV collagenase expression by down-regulating NF-kappa B binding to the promoter as a consequence of Ikappa Balpha-induced block of p65/p50 nuclear translocation. J Biol Chem 2001, 276:1164-1172.

35. Yoshioka K, Ohno Y, Horiguchi Y, Ozu C, Namiki K, Tachibana M: Effects of a KiSS-1 peptide, a metastasis suppressor gene, on the invasive ability of renal cell carcinoma cells through a modulation of a matrix metalloproteinase 2 expression. Life Sci 2008, 83:332-338.

36. Fahnestock M, Woo JE, Lopez GA, Snow J, Walz DA, Arici MJ, Mobley WC beta-NGFendopeptidase: structure and activity of a kallikrein encoded by the gene mGK-22. Biochemistry 1991, 30:3443-3450.

37. Castano JP, Martinez-Fuentes AJ, Gutierrez-Pascual E, Vaudry H, TenaSempere M, Malagon MM: Intracellular signaling pathways activated by kisspeptins through GPR54: do multiple signals underlie function diversity? Peptides 2009, 30:10-15

38. Nash KT, Welch DR: The KISS1 metastasis suppressor: mechanistic insights and clinical utility. Front Biosci 2006, 11:647-659.

39. Liu X, Lee K, Herbison AE: Kisspeptin excites gonadotropin-releasing hormone $(\mathrm{GnRH})$ neurons through a phospholipase $\mathrm{C} /$ calciumdependent pathway regulating multiple ion channels. Endocrinology 2008, 149:4605-4614.

40. Zhang C, Roepke TA, Kelly MJ, Rønnekleiv OK: Kisspeptin depolarizes gonadotropinreleasing hormone neurons through activation of TRPClike cationic channels. J Neurosci 2008, 28:4423-4434.

41. Coba MP, Valor LM, Kopanitsa MV, Afinowi NO, Grant SG: Kinase networks integrate profiles of N-methyl-D-aspartate receptor-mediated gene expression in hippocampus. J Biol Chem 2008, 283:34101-34107.

42. Heger S, Mastronardi C, Dissen GA, Lomniczi A, Cabrera R, Roth CL, Jung $H$, Galimi F, Sippell W, Ojeda SR: Enhanced at puberty 1 (EAP1) is a new transcriptional regulator of the female neuroendocrine reproductive axis. J Clin Invest 2007, 117:2145-2154

43. Ojeda SR, Hill J, Hill DF, Costa ME, Tapia V, Cornea A, Ma YJ: The Oct-2 POU domain gene in the neuroendocrine brain: a transcriptional regulator of mammalian puberty. Endocrinology 1999, 140:3774-3789.

44. Mastronardi C, Smiley GG, Raber J, Kusakabe T, Kawaguchi A, Matagne V, Dietzel A, Heger S, Mungenast AE, Cabrera R, Kimura S, Ojeda SR: Deletion of the Ttf1 gene in differentiated neurons disrupts female reproduction without impairing basal ganglia function. J Neurosci 2006, 26:13167-13179.

45. Ebling FJ, Brooks AN, Cronin AS, Ford H, Kerr JB: Estrogenic induction of spermatogenesis in the hypogonadal mouse. Endocrinology 2000, 141:2861-2869.

46. Poon SS, Wong JT, Saunders DN, Ma QC, McKinney S, Fee J, Aparicio SA Intensity calibration and automated cell cycle gating for highthroughput image-based siRNA screens of mammalian cells. Cytometry A 2008, 10:904-917.

47. Wu Z, Irizarry RA, Gentleman R, Murillo FM, Spencer F: A Model Based Background Adjustment for Oligonucleotide Expression Arrays. Journal of the American Statistical Association 2004, 99:909-917.

48. Applied Biosystems: Relative Quantitation Using Comparative Ct: Getting Started Guide.Edited by: Biosystems A. 7900HT Fast Real-Time PCR System. Foster City, California; 2005:

49. Pinheiro JC, Bates DM, ebrary Inc: Mixed-effects models in S and S-PLUS. Statistics and computing New York: Springer; 2000, xvi, p528.

50. Benjamini $Y$, Hochberg Y: Controlling the False Discovery Rate: A Practical and Powerful Approach to Multiple Testing. Journal of the Royal Statistical Society 1995, 57:289-300, Series B (Methodological).

51. Bates D: Linear mixed model implementation in Ime4. 2008 [http://cran. rproject.org/web/packages/Ime4/vignettes/Implementation.pdf].

52. R Development Core Team: R: A language and environment for statistical computing. R Foundation for Statistical Computing 2008 Vienna, Austria.

doi:10.1186/1471-2164-12-209

Cite this article as: Prentice et al.: The testosterone-dependent and independent transcriptional networks in the hypothalamus of Gpr54 and Kiss 1 knockout male mice are not fully equivalent. BMC Genomics 2011 12:209. 